Article

\title{
Bridging Tools to Better Understand Environmental Performances and Raw Materials Supply of Traction Batteries in the Future EU Fleet
}

\author{
Silvia Bobba ${ }^{1, *}$, Isabella Bianco ${ }^{2}$, Umberto Eynard ${ }^{1,2,3}$, Samuel Carrara ${ }^{4}$, Fabrice Mathieux ${ }^{1}$ (D) \\ and Gian Andrea Blengini ${ }^{1,2}$ \\ 1 European Commission, Joint Research Centre (JRC), 21027 Ispra, Italy; \\ umberto.eynard@ext.ec.europa.eu (U.E.); fabrice.mathieux@ec.europa.eu (F.M.); \\ gianandrea.blengini@ec.europa.eu (G.A.B.) \\ 2 Department of Environment, Land and Infrastructure Engineering, Politecnico di Torino, \\ Corso Duca degli Abruzzi 24, 10129 Torino, Italy; isabella.bianco@polito.it \\ 3 SEIDOR SBS Services, c/Pujades 350, 08019 Barcelona, Spain \\ 4 European Commission, Joint Research Centre (JRC), 1755 LE Petten, The Netherlands; \\ samuel.carrara@ec.europa.eu \\ * Correspondence: silvia.bobba@ec.europa.eu
}

Received: 10 April 2020; Accepted: 12 May 2020; Published: 15 May 2020

check for updates

\begin{abstract}
Sustainable and smart mobility and associated energy systems are key to decarbonise the EU and develop a clean, resource efficient, circular and carbon-neutral future. To achieve the 2030 and 2050 targets, technological and societal changes are needed. This transition will inevitably change the composition of the future EU fleet, with an increasing share of electric vehicles (xEVs). To assess the potential contribution of lithium-ion traction batteries (LIBs) in decreasing the environmental burdens of EU mobility, several aspects should be included. Even though environmental assessments of batteries along their life-cycle have been already conducted using life-cycle assessment, a single tool does not likely provide a complete overview of such a complex system. Complementary information is provided by material flow analysis and criticality assessment, with emphasis on supply risk. Bridging complementary aspects can better support decision-making, especially when different strategies are simultaneously tackled. The results point out that the future life-cycle GWP of traction LIBs will likely improve, mainly due to more environmental-friendly energy mix and improved recycling. Even though second-use will postpone available materials for recycling, both these end-of-life strategies allow keeping the values of materials in the circular economy, with recycling also contributing to mitigate the supply risk of Lithium and Nickel.
\end{abstract}

Keywords: Life Cycle Assessment (LCA); Material Flow Analysis (MFA); Criticality; traction batteries; forecast; supply

\section{Introduction}

Sustainable and smart mobility, when articulated with appropriate energy systems, is a key asset to decarbonise the EU and develop a clean, resource efficient and carbon-neutral future. This is confirmed by several policy initiatives, among others: the European Green Deal [1] and the EC COM(2019) 22 [2]. In addition, the transition towards a low-carbon mobility contributes to the United Nations Sustainable Development Goals (UN SGDs), for instance Goal 7-ensure access to affordable, reliable, sustainable and modern energy for all [1].

To achieve the 2030 and 2050 targets, technological and societal changes concerning mobility are needed. To improve circular economy and resource efficiency in the automotive sector, the technological 
aspects should cover the whole value chain of vehicles, from their design to their End-of-Life (EoL), e.g., new vehicles, light-weighting materials, easier reusability and recyclability of materials, recycled content in vehicles and transport infrastructure [2,3]. In addition, the behaviour of consumers should change toward choices oriented to more environmental-friendly practices, e.g., increase of the occupancy rate of vehicles and the adoption of public transport, sharing of vehicles, teleworking options [3,4]. Automation of vehicles is already proceeding but further efforts are required in the research field to reduce emission and avoid rebound effects (e.g., higher demand for mobility) [4].

This transition will inevitably change the composition of the EU fleet in the future: the increasing share of electric vehicles (xEVs) is already occurring and this trend is expected to accelerate in the next decade $[3,5,6]$. Meanwhile, new technologies can have an important role in the next future, even though nowadays they are at a very early stage, e.g., fuel cells electric vehicles [7]. Several scenarios are already available in the literature, considering new technologies appearing in the EU market and their evolution according to various parameters (environmental targets, consumers' lifestyles and behaviour, electric driving ranges, economic factors, etc.) (e.g., [6,8]). Such forecasts are quite complex to compare due to the adoption of different assumptions behind the models. Although there is no consensus in the scientific literature on a specific model to adopt in forecasting the uptake of $x E V s$, the trend is quite clear: xEVs will rapidly increase and will have a very important share on the EU fleet up to 2050, with a consequent increase of traction batteries required for such vehicles.

Among the traction batteries, the most common and most promising chemistry currently used in the EU market are the Li-ion batteries (LIB). The characteristics of LIBs are suitable for their use in different type of $x E V s$, especially battery electric vehicles (BEVs) and plug-in electric vehicles (PHEVs) [5]. Note that According to the scope of the analysis, since HEVs need relatively small batteries and will have a lower impact on the LIBs market, HEVs are not included in the following analysis.

When traction LIBs reach about $70-80 \%$ of their capacity, they are usually extracted from xEV and they have to be properly collected and recycled according to the in-force Directives (2000/53/EC and 2006/66/EC) [9]. However, pilots and research projects are demonstrating that the residual capacity of extracted batteries could be even used in less energy-demanding applications, e.g., residential buildings [9-11]. Even though the second-use of LIB is an industrial practice, there is potential for the creation of a business case beyond 2030 [5]. The second-use of batteries, before their recycling, is an example of circular economy practice where the value of batteries (and therefore embedded materials) is retained within the economy and the resource efficiency is maximised. On the other hand, the flow of batteries available for recycling is delayed in time, which means that also the availability of Secondary Raw Materials (SRMs) from waste batteries is postponed in time due to their higher lifetime [12]. Therefore, an in-depth knowledge of the processes along the value chain of complex products as LIBs is fundamental to assess the effects and the trade-offs of different strategies, e.g., the EoL options.

The New Circular Economy Action Plan [13] and the New Industrial Strategy for Europe (EC, 2020), two of the main building blocks of the European Green Deal [1], stress the role of Critical Raw Materials (CRMs) to achieve a climate-neutral, circular and competitive economy. Future sustainability requirements for batteries could in the future consider, for instance, the carbon footprint of battery manufacturing, ethical sourcing of raw materials and facilitating reuse, repurposing and recycling. Secure and sustainable supply of both primary and secondary raw materials for key technologies such as e-mobility is hence a prerequisite to achieve climate neutrality. With the transition of Europe's industry to climate-neutrality, the reliance on available fossil fuels could be replaced with reliance on non-energy raw materials, many of which are sourced from abroad and for which global competition is becoming more intense [14]. According to OECD forecasts, global demand for raw materials will more than double by 2060, making diversified sourcing essential to increase Europe's security of supply. CRMs are also crucial for markets such as e-mobility, batteries, renewable energies, pharmaceuticals, aerospace, defence and digital applications [15]. 
The performance of LIBs is related to various aspects, in particular to which materials are used in their cathodes and anodes [5]. The combination of the increasing demand for xEVs and the dynamics related to battery chemistries translate into a growing and diversified demand for raw materials; among the key materials for the manufacturing of high-performant LIBs, some have been classified as CRMs in the EU and/or worldwide [16], e.g., cobalt, natural graphite and lithium. The EU heavily relies on imports for many materials used in batteries. According to the EC Raw Materials Information System (RMIS-https://rmis.jrc.ec.europa.eu/), as the future demand of materials for strategic sectors is concerned, the EU will continue to be almost entirely dependent on third countries, in particular for traction batteries. In fact, the EU produces only $1 \%$ of all battery raw materials overall. Materials needed for the batteries manufacturing are mainly extracted in China (32\%), Africa and Latin America (both 21\%), but also the manufacturing process is mainly occurring in Asian countries. In this framework, some EU initiatives are focusing on improving the EU capacity in manufacturing batteries and improving the EU value chains (e.g., European Battery Alliance and Strategic Action Plan on Batteries).

Due to high cost of specific cathodes, e.g., Li-Co-based such as NMC (nickel-manganese-cobalt) or NCA (nickel-cobalt-aluminium), chemistries with lower cobalt content are already available [17,18]. For instance, the NMC111 is already replaced by cathodes with lower Co content, e.g., NMC811 or NMC9.5.5, which means a strong reduction of the cobalt and manganese content and an increase of nickel. Increased collection of end-of-life vehicles (ELVs) and boosting recycling could increase the amount of recovered materials that can be potentially recirculated in the economic system, i.e., their value is retained within the EU and the EU dependency can reduce [2,14]. The recovery of such materials is particularly relevant for the EU since they are materials with a high supply risk and high economic importance [19]. Note that nickel needed for the batteries manufacturing should belong to CLASS I nickel, i.e., $99 \%$ pure nickel $[20,21]$, which should be considered when assessing the recirculation of recovered nickel from recycling processes.

Recycling of the battery at its EoL can be advantageous from both resource conservation and environmental perspectives [22]. Recycling can provide SRMs that according to their quality can be used by the battery sector (e.g., cobalt) or by other industries [23], avoid the extraction of virgin raw materials and generally have lower environmental impacts.

Directive 2006/66/EC14 defines the minimum recycling rates of batteries: $45 \%$ of LIBs at their EoL have to be collected and at least $50 \%$ of the average weight of LIBs should be recycled, excluding energy recovery. Nevertheless, as underlined by Ellingsen et al. (2018) [22], this Directive often incentivises batteries industries to recover base metals, which are massively used and relatively abundant in nature and available in commodity markets (such as iron and copper). On the other hand, it is known that the market value of metals contained in batteries is an important economic driver for battery recycling. In particular, the higher prices of cobalt and nickel relatively can explain why recycling processes are currently focusing on these metals [22].

To assess the potential contribution of batteries in decreasing the environmental burdens of the EU mobility in the future, several aspects should be included in the assessment. Focusing on the environmental impacts of batteries along their life-cycle, in the literature Life-Cycle Assessment (LCA) studies are already available (e.g., [24-26]). However, "guidelines or harmonized approaches do not yet exist" [27] and some issues emerging from the available literature still need to be addressed [28], which make it even more challenging to capture the environmental performances of different type of traction batteries in $\mathrm{xEVs}$, especially in relation to the adoption of energy mix and taking into account different EoL options. Again, a single assessment tool does not likely provide a complete overview of such a complex system; in fact, some aspects are not captured through LCA, e.g., resource efficiency of some EoL options, hence LCA should be integrated with other assessment tools [29]. To obtain a more complete understanding of products' status [30], different assessment tools should be combined $[29,31,32]$. There are already some studies demonstrating the added value of combining LCA and (dynamic) Material Flow Analysis (MFA), which identify and quantify the stocks and flows 
of products/materials along their whole value chain. Bridging tools and the complementary use of their results support a more prospective decision-making, especially when different strategies are assessed, e.g., waste strategies [31]. Finally, the relevance of specific materials in terms of availability and vulnerability of a system, can be captured by the criticality assessments, providing relevant information of supply disruption and mitigation measures, taking into account flows of both primary and secondary materials [16].

Well established tools can be adapted and combined according to the product/system' characteristics to provide a wider understanding of the environmental performances in a life-cycle perspective. Hence, it is possible to capture different aspects of the assessed system/product and provide information according to the interests of the specific stakeholders. In addition, a flexible model and a common structure of the data collection (e.g., identification of best available sources, common data when possible) eases the update of the assessment according to the availability of data/information. Finally, consistency of input for different analyses is improved and the comparability of results is strengthened.

For a sustainable management of traction batteries, in an exponentially growing market and with a life-cycle perspective, some key questions need to be answered:

1. To what extent will the environmental performance of future mobility systems improve due to the uptake of EVs and therefore batteries? Is this improvement in line with expectations (e.g., the EU Green Deal and the SGDs)? How relevant is the relative contribution of traction LIBs life-cycle impacts in terms of environmental performance?

2. To cover the forecasted demand of traction LIBS for the EU fleet in the future, will the CRMs used for their manufacturing be available in adequate quantity and quality?

3. What can the role of recycling in terms of improving the environmental performances of LIBs be? To what extent can it contribute until the production of traction batteries peak and stabilise? At what stage of the LIB value chain are the CRMs to be recycled in the future (i.e., SRMs)?

4. In which way are CRMs key to the change of mobility patterns? In which way will the change in mobility patterns affect criticality, e.g., in terms of growing demand for $\mathrm{S}(\mathrm{C}) \mathrm{RMs})$ ?

5. How much can circular economy strategies help speed up the change and improve the overall environmental performance of mobility systems? How can trade-offs between different EoL strategies be quantitatively considered?

\section{Aim and Structure of the Paper}

This paper builds on a toolbox of existing assessment methodologies and bridges them to assess the environmental performances of complex systems. The adoption of different methodologies providing different type of information of the potential effects of the rapid evolution of a key sector for the EU is the core of the paper. For this reason, well established assessment tools are integrated: (1) to consider specific characteristics of the assessed LIBs; (2) to provide a more holistic and comprehensive understanding of traction LIBs; and (3) to build structured and comprehensive responses to relevant questions made by different stakeholders of the whole value chain of traction LIBs (e.g., manufacturers, recyclers, consumers and policy makers).

The authors believe that bridging tools and a more structured use of their results, as well as a mutual informing among the tools, is an added value in improving the knowledge of complex system and can support decision-making. The main focus of the performed assessment is the environmental performances of traction batteries (mainly LIBs) in decreasing the environmental burdens of the EU fleet up to 2050. In particular, LCA, MFA and criticality assessments, with emphasis on supply risk, are the three tools to bridge and use in a complementary manner. As mentioned in the Introduction, for this paper, the criticality of materials is used as filter to prioritise materials. The criticality of materials is used as filter to prioritise materials. In particular, among the key materials for the future development of batteries in the EU, as defined by the SWD (2018) 45, criticality of materials is used 
to identify those to be firstly studied. LCA is used to understand the environmental performance of traction batteries in the current and future EU fleet. MFA is used to trace flows in anthropogenic flow cycles, to understand the current and future demand of (C)RMs, including where they are stocked, when they will be available for recycling, etc. In a mutual fashion, criticality is used to prioritise the materials that undergo LCA and MFA, while LCA and MFA provide information to assess potential effects of variation of primary/secondary materials in terms of supply risk in the future (e.g., potential decrease of supply risk due to higher recycling).

The study also aimed at identifying synergies in gathering data and information to be used in the three methodologies and applied them to a specific case study.

A concise literature review about the main aspects affecting the environmental performances of traction batteries (in particular LIBs) is provided in Section 2. A short description of the methodologies is reported in Section 3 and the application to traction LIBs in the current and future EU fleet is described in Section 4. Section 5 summarises the main outcomes of the analysis, highlighting also the main limitations of the study. The main conclusions and further research needs are illustrated in Section 6.

\section{Literature Review: Main Aspects Affecting the Environmental Assessment of LIBs in the Future EU Fleet}

The research on $x E V$ batteries is currently significantly active and rapidly evolving, as proved by the annual number of publications focusing on EV increased since the 1990s [33,34] and the increasing number of patents worldwide focusing on EV [35]. This section reports the main outcomes of the performed literature review, mostly referred to scientific publications between 2016 and 2019, with some exceptions for particularly relevant data published during 2010-2015. The critical review was carried according to the main research questions presented in the Introduction.

Traction batteries are recognised as key components for the future uptake of $\mathrm{xEV}$ and for the decrease of the environmental impacts of the future EU mobility system $[13,17,36]$. Forecasts and market trends of LIBs are available in the literature from both policy and research studies and manufacturers declarations. Most of the consulted studies are characterised by an exponential increase of both BEVs and PHEVs in EU, although other studies suggest that the uptake of new technologies can be described through an S-curve [6,37]. The modelling of such a curve entails the definition of the saturation level, which depends on technological/economic/social aspects, e.g., increase of occupancy rate of cars, price of new vehicles, concept of mobility and social acceptance of new technologies (see Alonso Raposo et al. [3]). Due to the different scopes, but also modelling, boundaries and assumptions of the explored studies, the comparability of the future EU fleet is quite complex.

Many recent studies have focused on the life-cycle impacts of LIBs, recognising in LIBs the main element differentiating xEVs from ICEVs [38,39]. Even though LCA is a standardised (ISO 14040-44) [40] and mature methodology, more methodological efforts to quantify the life-cycle impact of LIBs are needed [9]. In 2018, the Product Environmental Footprint Category Rules (PEFCR) provided a "detailed and comprehensive technical guidance on how to conduct a PEF study" [41]; among the application fields covered by the document, traction LIBs are included. Despite the guidance, available results from different LCA studies on LIBs end up being very heterogeneous and it is still difficult to clearly define the environmental battery performances [42,43]. These discrepancies are due to different factors: lack, in many cases, of primary data; necessary simplifications and assumptions of the LCA model; and different chemistries of LIBs and therefore different performances [42]. In this context, Peters and Weil [44] started a deep work of review, selection of data and unification of the Life Cycle Inventories (LCIs) of LCA studies that were, until that moment, published on the manufacturing stage of batteries. Peters and Weil [44] analysed 79 studies developed between 2010 and 2016, but just five of these studies used exclusively own primary inventories and clearly disclosed the data [24-26,38]. Other LCA studies provide detailed LCI of LMO-NCM battery based on primary data [45], of NCA cell from its dismantling [46], of Li-Sulphur batteries integrating lab experimentations and theoretical 
modelling [47], and of lithium manganese batteries (LMO) and lithium iron phosphate batteries (LFP) collecting data from a manufacturer [48]. Among the above-mentioned LIBs, NMC could become the most used Li-ion battery chemistry in 2030, followed by LFP and NCA with a $40 \%$ combined market share [5].

Because of the growth of LIBs, the demand of raw materials for manufacturing will increase according to their content in different LIBs chemistries. An increasing number of studies aimed at quantifying the future demand of materials for LIBs, especially if such materials are critical (e.g., cobalt). MFA is often used to quantify the stocks and flows of materials in and between processes along the value chain of LIBs. Among the consulted studies, the majority adopt a global approach, while few focus on the EU value chain; in addition, the analyses often focus on the demand of primary raw materials without including the contribution deriving from SRMs. In addition, more circular options than recycling are arising in the EU. This is the case of extending the lifetime of LIBs, e.g., through their second-use in less energy-demanding applications [9,49]. Thus, a proper management of EoL can have benefits in terms of environmental impacts and supply of SRMs, as well as effects and trade-offs between different EoL options should be further explored to provide information to be used in properly manage waste batteries.

Focusing on the environmental impacts of reuse and second-use of batteries, relevant aspects to be considered in assessing the impacts of LIBs were identified. As the reuse is concerned, key aspects to be considered are electricity mix [50-52], efficiency losses of batteries [50,52] and the characteristics of both the battery and the second-use application [9,45,53-55]. Due to the novelty of the topic and the scarce availability of data, input data are often based on warranties of LIBs and assumptions [9].

As far as concern recycling, guidelines for the impact calculation of LIBs recycling are provided in the PEFCR on batteries [41]. Bobba et al. [12], using information from industries [56], assessed the impacts of different EoL options, mainly focusing of the materials assessment, i.e., through a dynamic MFA. R\&D projects and industrial companies are currently investing some efforts to improve the recovery of materials embedded in batteries to increase the sustainability of LIBs and tackle with economic barriers, which in some cases are important obstacles to the development of recycling at industrial scale, e.g., in the case of lithium recycling. For that reason, the amount of SRMs available in the future is expected to increase and contribute to partially cover the demand of raw materials for LIBs.

Available studies assessing criticality of raw materials were critically reviewed by Schrijvers et al. [16]. In this study, it is highlighted that different methods have been developed to identify criticality assessment factors and indicators at different levels (global, country or region, company, technology or specific products) [16]. In addition, data availability is recognised as a key factor that limits the evaluation of criticality. Proxies are needed to overcome this lack of data. Furthermore, data quality, including both data uncertainty and data representativeness, is rarely addressed in the interpretation and communication of results [16]. Focusing on the EU, the list of CRMs and the criticality methodology are a key instrument in the context of the EU raw materials policy, a precise commitment of the Raw Material Initiative [57]. Since the publication of the first list in 2011 and subsequent updates in 2014 and 2017, the EC criticality methodology responded to the needs of governments and industry to better monitor raw materials and inform decision makers on how security of supply can be achieved through diversification of supply, resource efficiency, recycling and substitution. To prioritise needs and actions at the EU level, the list of CRMs supports in negotiating trade agreements, challenging trade distortions and in programming the research and innovation funding. The EC methodology [58] defines CRMs as the combination of high economic importance (EI) for the EU and high risk of supply disruption (SR, supply risk). The assessment in essentially based on past data, e.g., the 2017 list was based on the five-year average (i.e., 2010-2014). Demand growth is often considered by technology-oriented methods, but not always considered by studies focusing on a national economy. This makes this exercise suitable to describe current economic situation, disregarding the future development of the economy [16]. 
The performed literature review highlights the complexity of the topic and the fact that several aspects should be taken into account to provide valuable and complete information on the environmental performances of traction LIBs in the EU in the future. In this framework, the integration of LCA and MFA to better understanding complex systems and environmental impacts is an added value [29,30,32]. Studies combining LCA and MFA of products are already available in the literature [31,59] and synergies between LCA and criticality were already proposed by Mancini et al. [60]. Specific consideration of future availability and demand of primary/secondary (critical) raw materials for traction LIBs in the EU were explored by Golroudbary et al. [61] and Pillot [62]. Song et al. [63] developed a detailed study on dynamic MFA of the CRMs for the Chinese LIB industry combining both the MFA and a CRMs evaluation model based on Blengini et al. [58] considering future scenarios up to 2025. Studies on the criticality of raw materials embedded in LIBs were investigated by Olivetti et al. [18] and Helbig et al. [64]. The results of criticality assessment and LCA were combined by Gemechu et al. [65]. However, the results do not provide specific information related to the potential variation of the supply risk due to the potential improvement of specific circular strategies and related environmental impacts. Finally, synergies among LCA, MFA and potential supply risk should be further improved at inventory level since some input data can serve all (e.g., processes efficiency and materials content).

The literature review confirms that, to the authors' knowledge, there are no studies specifically addressing traction batteries in the EU along their whole value chain integrating information provided by all LCA, MFA and supply risk considerations together. In addition, a future-oriented approach requires more scientific efforts in terms of methodology, to develop models taking into account key aspects of foreseeable future, e.g., physical scarcity or the future development of the economy [16].

\section{Methodology: Modelling Flows and Impacts of LIBs in the EU Fleet}

The integration of assessment tools able to analyse different but complementary aspects is a key feature to improve an in-depth and comprehensive knowledge of the EU fleet. In the following paragraphs, the main features of performed assessment of the environmental impact of traction LIBs in the EU fleet are illustrated.

A Life-Cycle Thinking (LCT) approach is adopted to include in the assessment all the relevant aspects along the whole value chain of products, taking also into account external aspects affecting environmental performances of products, e.g., socioeconomic aspects.

\subsection{LCA of Traction LIBS}

The developed LCA follows the (ISO 14040-44) and the PEFCR for batteries [41]. The LCA tool provides the necessary background information on environmental impacts of products/services under analysis along their whole value chain. Considering the potential development of technology and the complexity of some products, the development of modular LCAs and the adoption of parameters make the LCA model flexible: (1) to update according to available input data; (2) to speed-up the LCAs of different products; and (3) to enlarge the analysis (e.g., new materials and/or components).

According to PEFCR for batteries, the functional unit (F.U.) for rechargeable batteries can be defined as $1 \mathrm{kWh}$ of the total energy provided over the service life by the battery system. Nevertheless, this functional unit requires referring to the expectancy life of the battery, which is often hard to estimate because it is affected by many different parameters [10,42]. Moreover, since the majority of available LCA studies on batteries show impact results for $1 \mathrm{~kg}$ of battery or for $1 \mathrm{Wh}$ of storage capacity, the developed LCA tool provides results for both $1 \mathrm{kWh}$ of energy provided and $1 \mathrm{~kg}$ of battery pack. The LCA tool provides information on the specific LCI datasets used for the analysis, with reference to Environmental Footprint (EF) and Ecoinvent databases (see Supplementary Materials for details). Datasets are connected to the related impacts, evaluated with the EF method; this enables the user to easily assess the batteries for all the impact categories available within this method. In this manuscript, attention is however focused on the Global Warming Potential (GWP), as one of the most 
robust categories and of high societal and policy interest [66]. Results for the other EF impact categories are reported in the Supplementary Materials.

The unified database of Peters and Weil [44] is used to assess the environmental impacts of different LIBs chemistries according to available inventories in the literature. In addition, this analysis updates and extends the unified database with recent data on the manufacturing of LIBs data [45,46] and on other stages of batteries life-cycle (use and EoL stages). Table 1 lists the main characteristics of the analysed batteries and the selected source of the LCI data.

Table 1. Main characteristics of the analysed batteries and the selected source of the LCI data.

\begin{tabular}{ccccccc}
\hline $\begin{array}{c}\text { Battery } \\
\text { Chemistry }\end{array}$ & $\begin{array}{c}\text { Type of } \\
\text { Vehicle }\end{array}$ & $\begin{array}{c}\text { Weight } \\
{[\mathbf{k g}]}\end{array}$ & $\begin{array}{c}\text { Capacity } \\
{[\mathbf{k W h}]}\end{array}$ & $\begin{array}{c}\text { LCI Data Source for } \\
\text { Manufacturing Stage }\end{array}$ & $\begin{array}{c}\text { LCI Data Source } \\
\text { for Use Stage }\end{array}$ & $\begin{array}{c}\text { LCI Data Source } \\
\text { for EoL Stage }\end{array}$ \\
\hline NMC 111 & EV & 253 & 26.6 & {$[24,44]$} & {$[41]$} & {$[41,45,67]$} \\
\hline NMC 424 & EV & n.a. & n.a. & {$[26,44]$} & {$[41]$} & {$[41,45,67]$} \\
\hline NCA & EV & 142 & 18.9 & {$[44,68]$} & {$[41]$} & {$[41,45,67]$} \\
\hline NCA & EV & 154 & 20 & {$[46]$} & {$[41]$} & {$[41,45,67]$} \\
\hline LMO/NMC & PHEV & 175 & 11.4 & {$[45]$} & {$[41]$} & {$[41,45,67]$} \\
\hline
\end{tabular}

The use stage is defined by the energy losses due to the battery and charger efficiency [41]. The model was built in a way that the total energy used by a xEV before replacing the traction LIB is obtained by multiplying the distance covered by vehicles and the average fuel economy (energy necessary to cover the distance of $1 \mathrm{~km}$ ). The change of the energy mix along time is considering through an increasing share of renewables in the energy mix, based on EC projections [69,70].

The EoL stage includes dismantling of components, the conversion into recycled material, other operations and credits connected to the re-availability of material after the recycling process [41]. The LCI of the EoL stage was unified with reference to data provided by the PEFCR on batteries, with exception of input/output data of lithium, nickel, manganese, cobalt, graphite, copper and aluminium. For these latter, quantities of recycled material (and consequent credits) were calculated considering the amount of materials available in each battery and the recovery of the same material after the recycling process.

To make the LCA replicable and updatable, the LCI of each LIB chemistry is provided in a spreadsheet (included in the Supplementary Materials), where each input/output flow of material, energy, waste and emission is related to $1 \mathrm{~kg}$ of battery pack. Each flow is connected to the related impacts, enabling the automatic calculation of the impact of the battery life-cycle. The changing of input/output quantities or parameter values allows the evaluation of different scenarios, as shown in Section 5. Moreover, the modularity of the model allows quick and consistent comparisons between environmental performances of different batteries. Additionally, due to the fast development of the technology, the modularity of the LCA model allows enlarging it, adding e.g., new materials and/or components.

\subsection{MFA of traction LIBs in the EU}

MFA is used to better understand the value chain of products through the representation of the main processes along the value chain but also to quantify the stocks and flow of products/materials over time [71].

According to Bobba et al. [12], the adoption of parameters in the MFA model makes it customisable and flexible to assess different scenarios and identifying e.g., circular economy aspects and/or effects of EoL options along the whole value chain of LIBs. In addition, the modularity of the model allows easily adding/updating modules within the MFA model in case of new/more data would be available. In case some modules are not of interest of the assessment (e.g., second-use of specific LIBs' chemistries or in addressing some future EoL scenarios), parameters allow simply not considering these modules 
for the quantification of stocks and flows. In addition, different aspects of LIBs can be assessed, i.e., stocks and flows of both batteries, materials embedded in LIBs and storage energy capacity.

Figure 1 shows the MFA model created to estimate the stocks and flow of the EU fleet in the future. Differently from Bobba et al. [12], the model was enlarged to also include the recirculation of SRMs in the system and incineration/landfilling of LIBs. Due to the difficulty in collecting all the needed data, some flows were estimated through the adoption of a parameter which was made varying in-time. In line with the goal of the study, the model is used to quantify the stocks and flows of traction LIBs, lithium, nickel and the energy storage capacity for various LIBs chemistries and applications (i.e., PHEV and BEVs).

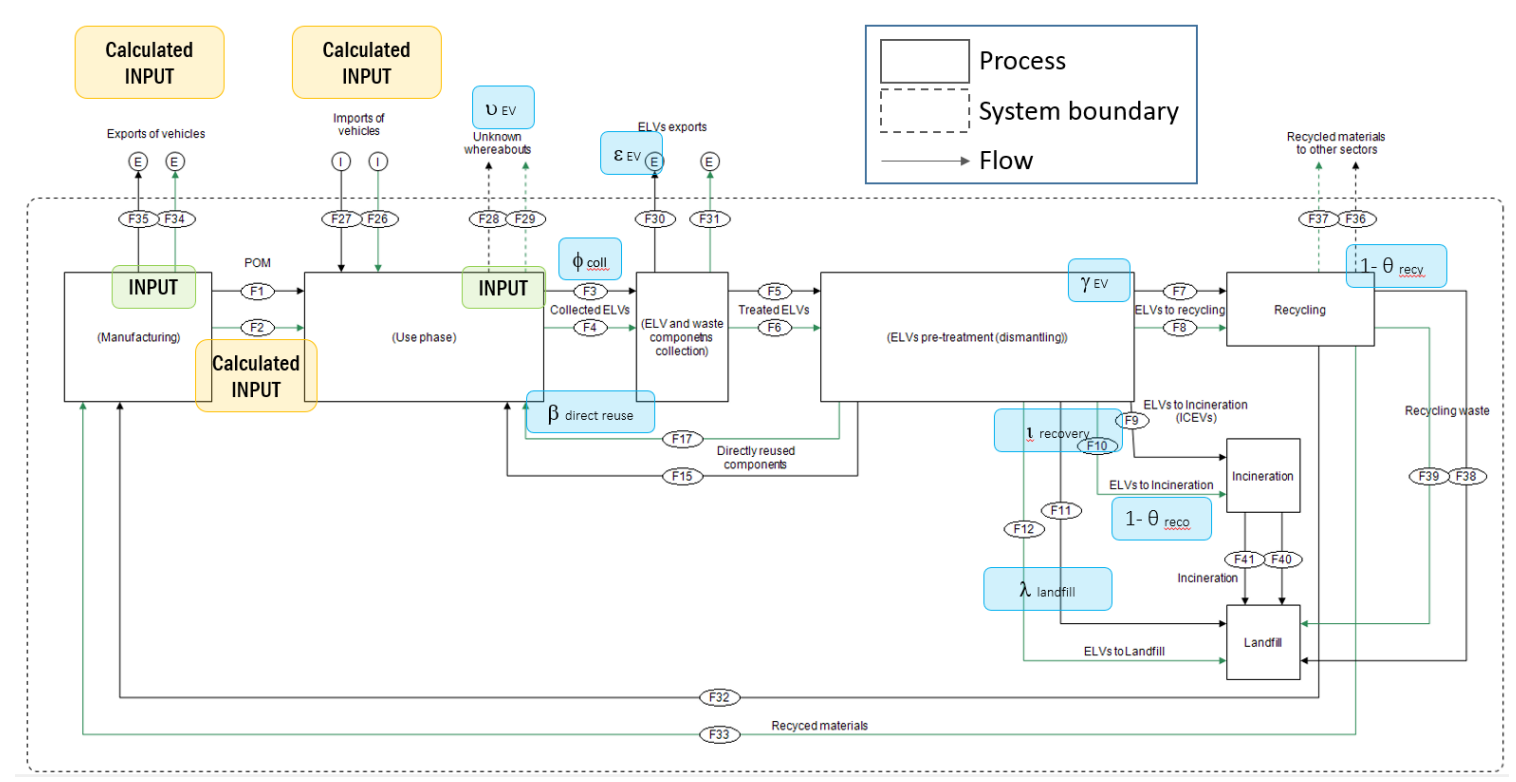

Figure 1. Modelling of stocks and flows of LIBs in the EU (adapted from Bobba et al. [12]).

Where:

$\begin{array}{ll}v_{\mathrm{ICEV} / \mathrm{EV}, \mathrm{y}} & =\text { Unknown whereabouts } \\ \phi \text { coll, } \mathrm{y} & =\text { Collected ELVs } \\ \varepsilon_{\mathrm{EV}, \mathrm{y}} & =\text { ELVs exports } \\ \gamma_{\mathrm{EV}} & =\text { ELVs to recycling } \\ \iota_{\text {recovery }} & =\text { ELVs to recovery } \\ \beta_{\text {direct reuse }} & =\text { ELVs to direct reuse } \\ \lambda_{\text {recovery }} & =\text { ELVs to landfill } \\ \theta_{\text {recy }} & =\text { Recycling efficiency } \\ \theta_{\text {reco }} & =\text { Recovery efficiency }\end{array}$

\subsection{Criticality and Supply Risk of LIBs Raw Materials}

According to Schrijvers et al. [16], "the raw material criticality is the field of study that evaluates the economic and technical dependency on a certain material, as well as the probability of supply disruptions, for a defined stakeholder group within a certain time frame". In line with the system boundary of the study, the analysis on materials supply risk is applied at EU level, focusing on battery's raw materials. As mentioned in Section 2, the EC methodology [58] defines CRMs as the combination of high economic importance (EI) for the EU and high risk of supply disruption (SR, supply risk).

In this paper, we focus on the contribution of recycling as a supply risk mitigation factor, according to the EC methodology [58]. Recycling of end-of-life products is in fact considered a more secure source of raw materials, in comparison to primary production [58].

The battery materials initially prioritised in this study include cobalt, lithium, natural graphite and nickel; manganese is considered too, although less often identified as CRMs $[16,72]$ due to the lower 
supply concentration and subsequent lower supply risk. Among the batteries' materials, technologies for recycling Li are currently available in the EU, even though not yet at industrial scale $[73,74]$. Concerning nickel, it is to be considered that nickel used for manufacturing traction LIBs needs to be of high quality; in fact, Nickel Class I has a Ni content higher than 99\% [20]. Despite some examples of high-quality nickel recovered from batteries (e.g., [75]), most of the nickel recycled nowadays is not suitable for the manufacturing of new LIBs [76]. In the EU, stainless steel is the biggest user of primary and scrap nickel, which already uses nickel scrap recycling for stainless steel production and will increase by 2025 .

Despite limitations, data provided by MFA, in particular amount of materials recovered from traction LIBs recycling, are used to estimate the potential reduction of the $\mathrm{SR}$ for both $\mathrm{Li}$ and $\mathrm{Ni}$ in relation to the expected evolution of the EU fleet.

\subsection{Common Inventory and Data Gaps}

Availability of data is a key point for all the above illustrated assessment methodologies. In some cases, the same data can serve two or three components, which is an added value for an already difficult data collection. Moreover, the adoption of the same data and/or information improve the consistency of the obtained results and ease the replicability of the assessment in case new data will be available in the future. Finally, a common inventory facilitates the clear definition of the needed assumptions for the three components.

Table 2 provides an overview of the data and assumptions included in the study that are common to at least two out of the three components. However, it is highlighted that the adoption of the same data for multiple components requires more efforts in terms of data quality and geographical/temporal representativeness.

Table 2. Overview of possible synergies between LCA, MFA and Criticality (supply risk) in terms of inventory data.

\begin{tabular}{|c|c|c|c|c|c|}
\hline & LCA & MFA & $\begin{array}{c}\text { Criticality } \\
\text { (Supply Risk) }\end{array}$ & Unit & Notes \\
\hline $\begin{array}{l}\text { Weight of the } \\
\text { battery }\end{array}$ & $x$ & $x$ & & {$[\mathrm{~kg}]$} & \\
\hline Lifetime & $x$ & $x$ & & $\begin{array}{l}\text { [year] or } \\
\text { [provided } \\
\text { kWh] }\end{array}$ & \\
\hline Materials content & $x$ & $x$ & $\mathrm{x}$ & $\begin{array}{c}{[\mathrm{kg} / \mathrm{kg} \text { battery }]} \\
\text { of }[\mathrm{kg} / \mathrm{kWh}]\end{array}$ & \\
\hline $\begin{array}{l}\text { Process efficiency } \\
\text { (i.e., losses) }\end{array}$ & $x$ & $x$ & & {$[\mathrm{~kg} / \mathrm{kg}$ battery] } & \\
\hline Import/export & for transport & $\begin{array}{l}\text { for flows } \\
\text { and stocks }\end{array}$ & $x$ & [tonne] & $\begin{array}{l}\text { - impacts of transport } \\
\text { - outbound/inbound flows } \\
\text { - import reliance }\end{array}$ \\
\hline Collection rate & $x$ & $x$ & & {$[-]$} & - indirectly availability of SRMs \\
\hline Battery reuse & $x$ & $x$ & $x$ & [\%] & $\begin{array}{l}\text { - lower impact of the battery life-cycle } \\
\text { (longer lifetime) } \\
\text { - stocks increase, creation of new stocks } \\
\text { - indirectly availability of SRMs }\end{array}$ \\
\hline $\begin{array}{l}\text { Battery } \\
\text { dismantling } \\
\text { efficiency }\end{array}$ & $x$ & $x$ & & {$[\%]$} & \\
\hline $\begin{array}{l}\text { Recycling } \\
\text { efficiency }\end{array}$ & $x$ & $x$ & $x$ & {$[\%]$} & $\begin{array}{c}\text { - impacts of recycling process / } \\
\text { avoided materials } \\
\text { - available SRMs to be recirculated in } \\
\text { the system }\end{array}$ \\
\hline $\begin{array}{l}\text { Quality of } \\
\text { recycled } \\
\text { materials }\end{array}$ & $x$ & $x$ & $x$ & {$[-]$} & $\begin{array}{l}\text { - closed/open loop } \\
\text { - available SRMs for specific sectors }\end{array}$ \\
\hline
\end{tabular}


Table 2. Cont.

\begin{tabular}{|c|c|c|c|c|c|}
\hline & LCA & MFA & $\begin{array}{c}\text { Criticality } \\
\text { (Supply Risk) }\end{array}$ & Unit & Notes \\
\hline $\begin{array}{c}\text { Materials } \\
\text { substitutability }\end{array}$ & $x$ & $x$ & $x$ & {$[-]$} & $\begin{array}{l}\text { - increase/decrease of materials content } \\
\text { - LCA of different chemistries }\end{array}$ \\
\hline $\begin{array}{l}\text { Future } \\
\text { technological } \\
\text { change }\end{array}$ & $x$ & $x$ & $x$ & {$[-]$} & $\begin{array}{l}\text { - different chemistries, } \\
\text { materials, components } \\
\text { - potential improve of } \\
\text { recycling technologies }\end{array}$ \\
\hline $\begin{array}{l}\text { Geographical } \\
\text { considerations }\end{array}$ & $x$ & $x$ & $\begin{array}{l}\mathrm{X} \text { (import } \\
\text { reliance and } \\
\text { production) }\end{array}$ & {$[-]$} & $\begin{array}{c}\text { - evaluate transports and } \\
\text { import/export flows } \\
\text { - EU dependency on third Countries } \\
\text { - import reliance }\end{array}$ \\
\hline WGI & $\begin{array}{l}\text { Social (not } \\
\text { assessed in } \\
\text { this study) }\end{array}$ & & $x$ & {$[-]$} & \\
\hline $\begin{array}{l}\text { New energy } \\
\text { sources }\end{array}$ & $x$ & & $x$ & {$[-]$} & \\
\hline $\begin{array}{l}\text { Trade agreements } \\
\text { and restrictions }\end{array}$ & & $x$ & $x$ & {$[-]$} & \\
\hline
\end{tabular}

\section{Case-Study: Traction Batteries in the Future EU Fleet}

The selected methodologies were applied to traction LIBs in the EU fleet between 2015 and 2030 to assess the environmental contribution of traction LIBs to the potential decrease of the impacts of the EU fleet in the next decades, but also the role of the key materials embedded in batteries. In this section, a brief description of the case-study is provided; to assess the potential added value of the coordinated approach, different scenarios were considered.

\subsection{Description of the Case-study and the Assessed Scenarios}

The environmental assessment focuses on traction batteries used in both PHEVs and BEVs, especially on LIBs embedding $\mathrm{Ni}$ and $\mathrm{Li}$. Note that, even though some LIBs are already used for HEVs, this technology was excluded from the analysis since the main power source is a combustion engine. A Base-Case Scenario was created to capture most of the aspects mentioned in the research questions (Section 1); in addition, the effects of some key aspects (i.e., EoL management and change of energy mix) are considered through the creation of ad-hoc scenarios hereinafter described (see Table 3).

\subsection{1. "Base-Case Scenario"}

The evolution of BEVs and PHEVs in EU between 2015 and 2030 is based on the EU Long-Term Strategy (LTS $1.5^{\circ} \mathrm{C}$ Technical), which assumes a reduction of the EU greenhouse gas emissions for 2030 of about $50 \%$ and zero emissions in 2050 [4].

The case-study is mainly focused on traction NMC and NCA chemistries, which are expected to dominate the traction LIBs EU market in the future (Section 2); LMO/NMC chemistry is also included in the analyses of current scenarios, while it is excluded in the calculations of future scenarios because of the scarce availability of data on possible trends for these chemistries. For the use stage of LIBs, the default amount for energy density is $9.6 \mathrm{kWh} / \mathrm{kg}$ (aligned with the PEFCR for batteries) and fixed for all the LIBs. Default values for the battery use are: 100,000 km for the driven distance (in line with the warranty generally given for batteries by BEV producers) and a fuel economy of $0.2 \mathrm{kWh} / \mathrm{km}$ (according to Fuel Economy data provided by EPA). For the EoL, no remanufacturing and second-use are assumed to develop at industrial scale in the EU. The recuperation of materials is calculated as the product of the collection rate, the dismantling rate and recycling rate. A collection rate of $95 \%$ is assumed, according to the PEFCR [41], and the recycling rate is based on Lebedeva et al. [74] and Cusenza et al. [45]. These rates are parameters which can be easily modified for assessing future scenarios. 
The specific energy mix considered in the study is based on literature data $[69,70]$. The estimation of the stocks and flows of LIBs/energy storage capacity/embedded materials is adapted from [12], with additional modules and flows; the value chain of batteries in the EU (Figure 2) is assumed to mainly maintain the current characteristics. This means that the manufacturing of batteries is assumed in the EU, according to Peters and Weil [44].

Concerning the assessment of $\mathrm{Li}$ and $\mathrm{Ni}$, as representative of key materials in the battery sector for the EU, their content in LIBs is assumed to vary in time according to available roadmaps (e.g., [5,72,74,77]). Currently, the recirculation of $\mathrm{Li}$ and $\mathrm{Ni}$ in a closed loop (i.e., to manufacture new LIBs) is almost null. The recovery of Li is not yet developed at industrial scale in the EU, mainly due to economic reasons [73,74]; therefore, it is assumed a current recycling efficiency equal to $1 \%$ in 2018 [41], linearly increasing in the future thanks to the ongoing research activities (up to $3 \%$ in 2030). On the other hand, the recycling rate of $\mathrm{Ni}$ is already quite high, i.e., 96\% [41]; however, to be used for manufacturing new cathodes, the purity of Ni has to be very high, and, according to the authors' knowledge, there are few examples of companies that are using secondary Ni to manufacture new cathode (e.g., [78]).

\subsubsection{Scenario A: Extension of the LIBs Lifetime Through Their Second-use}

Second-use of batteries in less energy demanding applications is an EoL option that can reduce the environmental impacts and boost resource efficiency [79]. Despite not yet occurring at large scale in the EU, the ongoing pilots and research activities have demonstrated that this option is valid and can increase in the next decades, if also supported by an adequate regulatory framework. Therefore, based on the Base-Case Scenario, Scenario A was created to assess the environmental effects of extending the lifetime of batteries. In particular, the life-cycle impacts include both the first- and second-use, the energy storage capacity of LIBs is further exploited before their recycling and the embedded materials are locked in the in-use stock for longer compared to the Base-Case Scenario.

The total amount of energy that is provided by the battery during its first and eventually second life is quite complex, since it depends on different connected variables, e.g., depth of discharge (DoD), charging-rate and operation temperature [10,42], and the environmental benefits depends on both the LIB's and the system's characteristics [9]. For this study, Scenario A considers a default value of $20,000 \mathrm{kWh}$ provided by the xEV battery first life and a second life providing $5143 \mathrm{kWh}$, according to Bobba et al. [9,12]. A linear increase of second-use of batteries from $0 \%$ (current situation) to $10 \%$ in 2030 and $30 \%$ in 2050 is assumed.

4.1.3. Scenario B: Improved EoL Extension of the LIBs Lifetime Through Their Second-use and Improvement of Recycling

Recovery of key materials is essential to decrease the dependency of the EU from third countries (Section 3.3). Then, the effects of an improvement in the management of EoL practices in terms of both second-use of LIBs and improved recycling efficiency is assessed in Scenario B. The trend of LIBs in second-use applications is the same as in Scenario A. In addition, it is assumed that the recycling technology allows higher recycling efficiency of $\mathrm{Li}(15 \%$ in 2030 and 2050) and higher level of purity for covered $\mathrm{Ni}$, which can be used again to manufacture LIBs (linear increase of the closed loop of $\mathrm{Ni}$, from $0 \%$ to $25 \%$ between 2018 and 2030).

\subsubsection{Scenario C: Renewable Energy for the Manufacturing Stage}

The amount and the source of energy used in the life cycle of LIBs can highly influence its environmental performance [24,80-82]. Currently, there are examples of producers of LIBs' cells that are using high share of renewables in the production process, e.g., Tesla and Northvolt Ett. In particular, Tesla claims to design its Gigafactory 1 in Nevada to be completely powered by solar array installed on its roof and wind turbine installed nearby, while Northvolt Ett declares that its plant in Sweden will rely on clean electricity from wind and hydroelectric power [83]. 
Hence, to observe the effects of a more environmental-friendly energy mix in the life-cycle of LIBs, Scenario $\mathrm{C}$ assumes that electricity for battery manufacturing is equally provided by photovoltaic panels, wind turbines and hydroelectric plants. All other input/output flows and related variables follow the Base-Case Scenario.

Table 3. Summary of the main differences between assessed scenarios.

\begin{tabular}{|c|c|c|c|c|}
\hline \multirow[b]{2}{*}{ Variables } & \multicolumn{4}{|c|}{ Scenarios } \\
\hline & $\begin{array}{l}\text { Base-Case } \\
\text { Scenario }\end{array}$ & Scenario A & Scenario B & Scenario C \\
\hline $\begin{array}{l}\text { Change in European energy mix } \\
\text { (current/2030/2050) }\end{array}$ & $x$ & $x$ & $x$ & $x$ \\
\hline $\begin{array}{l}\text { Change in battery material contents } \\
\text { (current/2030/2050) }\end{array}$ & $x$ & $x$ & $x$ & $x$ \\
\hline $\begin{array}{l}\text { Batteries are reused in a second life ( } 10 \% \text { in } 2030 ; \\
30 \% \text { in } 2050)\end{array}$ & & $x$ & $x$ & \\
\hline $\begin{array}{l}\text { The recycling rate of lithium and nickel is } \\
\text { enhanced }(2030 / 2050)\end{array}$ & & & $X$ & \\
\hline $\begin{array}{l}\text { Energy for manufacturing is completely } \\
\text { provided by renewable sources } \\
\text { (current/2030/2050) }\end{array}$ & & & & $x$ \\
\hline
\end{tabular}

\section{Results and Discussion}

Section 5 reports the main outcomes of the assessment. In particular, for the LCA analysis, results are reported on GWP impacts provided by the LCA tool for $1 \mathrm{kWh}$ of the total energy provided by the battery during its entire life-cycle. Note that, as previously discussed, this latter F.U. is influenced by the battery lifetime, which is by default set to $20,000 \mathrm{kWh}$ for all the analysed batteries. In addition, results reported in Section 5 mainly refer to the NMC and NCA chemistries as most of the consulted sources provide information of future trends of these two chemistries and almost no data about the uptake of LMO/NMC batteries are available.

\subsection{Results}

The Life-Cycle Impact Assessment (LCIA) of the assessed LIBs shows that the current life-cycle GWP is on average $0.16 \mathrm{~kg} \mathrm{CO} 2 \mathrm{eq} / \mathrm{kWh}$. The impact of NMC batteries results slightly higher than the NCA one. This difference could be partly due to the different material composition and partly to the higher mass of NCM batteries. The contribution analysis confirmed that the manufacturing stage highly contributes to the life-cycle GWP. In addition, the EoL recycling can reduce the impact of the battery by $22 \%$ on average. Among the LIBs' chemistries, the NMC 111 battery manufacturing has the highest impacts per kWh of provided energy. At the same time, NMC shows the highest benefit from its recycling, mainly related to the credits due to the availability of secondary raw materials after the battery recycling, mainly copper, nickel sulphate and cobalt sulphate. In the Base-Case Scenario, it is highlighted that the change of materials in different LIBs (e.g., from NMC111 to NMC811) and the increase of renewable energy share lead to a decrease of GWP in time (Figure 2). The manufacturing impacts of NMC batteries will decrease by $22 \%$ and $31 \%$ in 2030 and 2050 compared to the NMC nowadays in the market (2010-2018), while the reduction is lower ( $9 \%$ and $15 \%$ ) for NCA batteries manufacturing. High reductions are observed for the use stage: about $42 \%$ in 2030 and $56 \%$ in 2050 for both chemistries. 


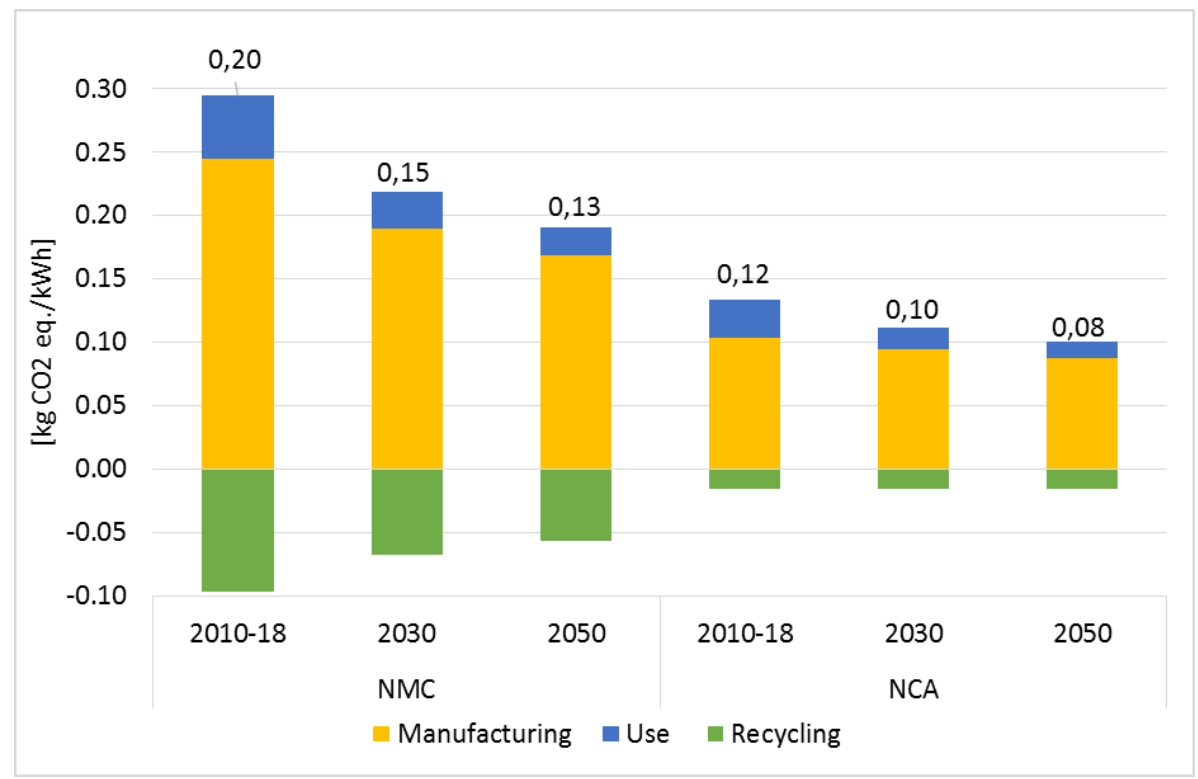

Figure 2. Life-cycle Global Warming Potential (GWP) of NMC and NCA chemistries in the Base-Case Scenario for different years. Labels at the top of each column indicate the respective values of the life-cycle GWP.

Focusing on the MFA, the results of the Base-Case Scenario show that the increasing demand of LIBs in the EU will not significantly affect the energy capacity storage and materials flows in the EU until 2030; then, waste flows start to be relevant in terms of quantities, especially recycling flows. Figure 3 shows an example of stocks and flows of energy capacity and materials in the studied system (for interpretation of the references to colour in this figure legend, the reader is referred to the web version of this article). Combining the above-illustrated GWP and energy storage capacity of LIBs placed on the EU market, it is estimated that the GWP of traction LIBs entering in EU fleet in 2015 is about $12 \mathrm{kt}$ of $\mathrm{CO}_{2}$ eq., and it will increase up to $35 \mathrm{kt}$ in 2030 and $95 \mathrm{kt}$ in 2050.

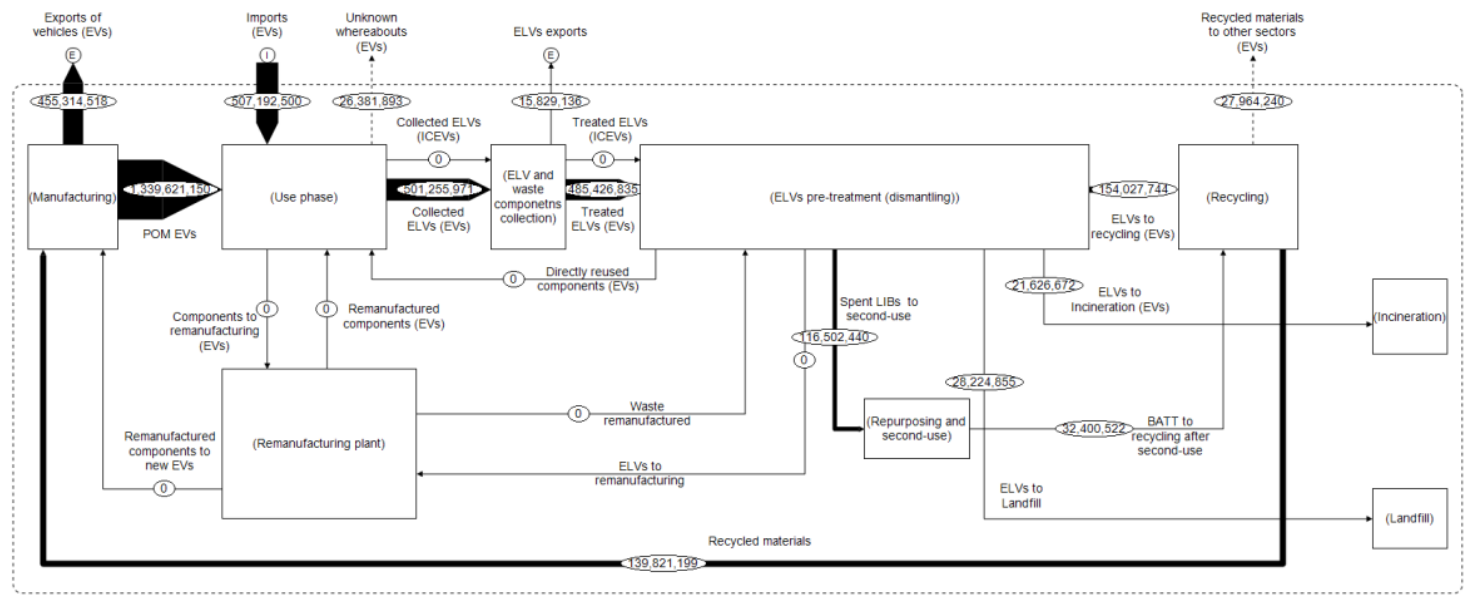

Figure 3. Flows of energy capacity storage in the EU in 2050.

Focusing on materials embedded in batteries, is observed that the amount of Li required for traction LIBs demand in 2030 and 2050 is, respectively, five and seven times higher than the 2020 demand (Figure 4). For Ni, these values increase to 7 and 14 times. Once extracted from EVs, the amount of $\mathrm{Li} / \mathrm{Ni}$ entering in the recycling process can potentially provide $7 \%$ of the $\mathrm{Li} / \mathrm{Ni}$ demand in 2030 and $26 \%$ in 2050. However, the recovered $\mathrm{Li}$ in 2030 is lower than 40 tonnes in 2030 and about 400 tonnes in 2050 , mainly due to the lack of recycling processes at industrial scale; similarly, the recovered $\mathrm{Ni}$ in 
2030 is about 900 tonnes and 11,000 tonnes in 2050. Note that almost all the recovered Ni is recycled in an open-loop, hence not used for manufacturing new LIBs. Secondary $\mathrm{Li}$ is lower than $0.5 \%$ of the $\mathrm{Li}$ demand in 2030, while secondary $\mathrm{Ni}$ is $0.4 \%$ of Ni demand for LIBs; these values slightly increase up to $1 \%$ for $\mathrm{Li}$ and to $2.5 \%$ for $\mathrm{Ni}$ in 2050 .

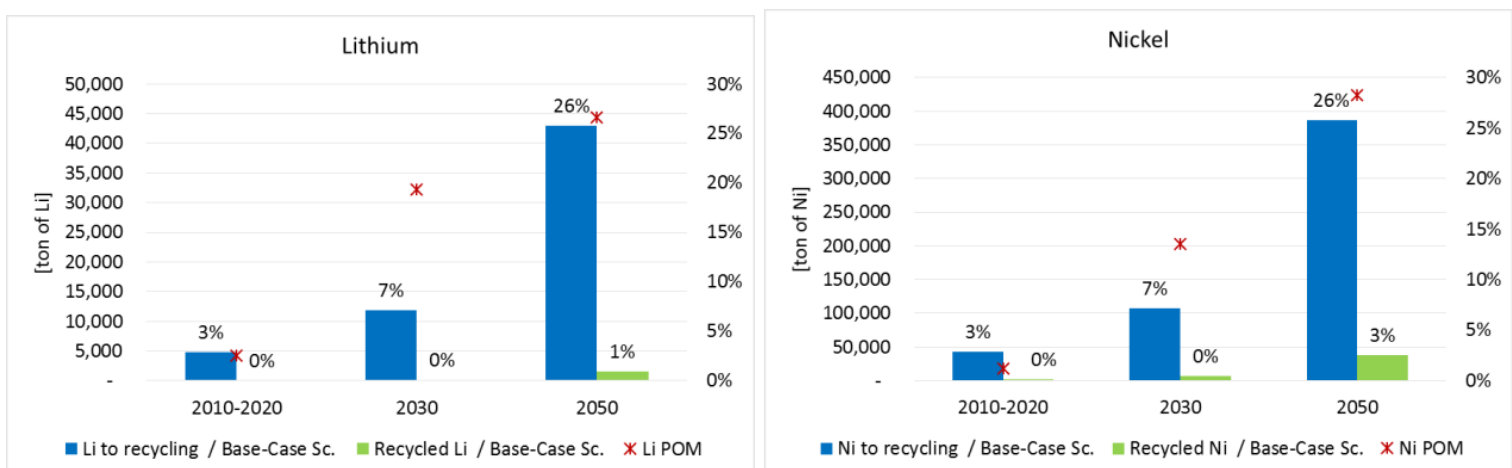

Figure 4. Li and Ni embedded in traction LIBs placed on the EU market (POM), available for recycling and recovered in different years.

If second-use will develop in the EU (Scenario A), LIBs and embedded materials will last longer within the system, decreasing the life-cycle impacts and postponing the amount of materials available for recycling. Assuming a second-life providing additional $5143 \mathrm{kWh}$, the GWP impact per kWh of provided energy necessarily decreases. With the assumption that the percentage of reused batteries is of $10 \%$ in 2030 and 30\% in 2050, the LCIA results show an average GWP reduction, respectively, of 3\% and $8 \%$ (Figure 5). If, in addition to the reuse of batteries, the recycling efficiency of LIBs will increase in time (Scenario B), reductions of 11\% and 17\% are observed for NMC in 2030 and 2050, respectively. The reduction is lower for the NCA chemistry: 4\% and 9\% in 2030 and 2050, respectively (Figure 5).

The adoption of a completely renewable energy mix for the NMC and NCA manufacturing (Scenario C) decreases the GWP of the manufacturing stage for both the current and future scenarios (see also Supplementary Materials). Benefits of manufacturing plants powered by renewables become progressively less evident over time, because of the enhanced sustainability of the European energy mix in 2030 and 2050. Compared to the Base-Case Scenario, Scenario C shows a GWP reduction of $23 \%$ in the current situation, $15 \%$ in 2030 and $12 \%$ in 2050 .

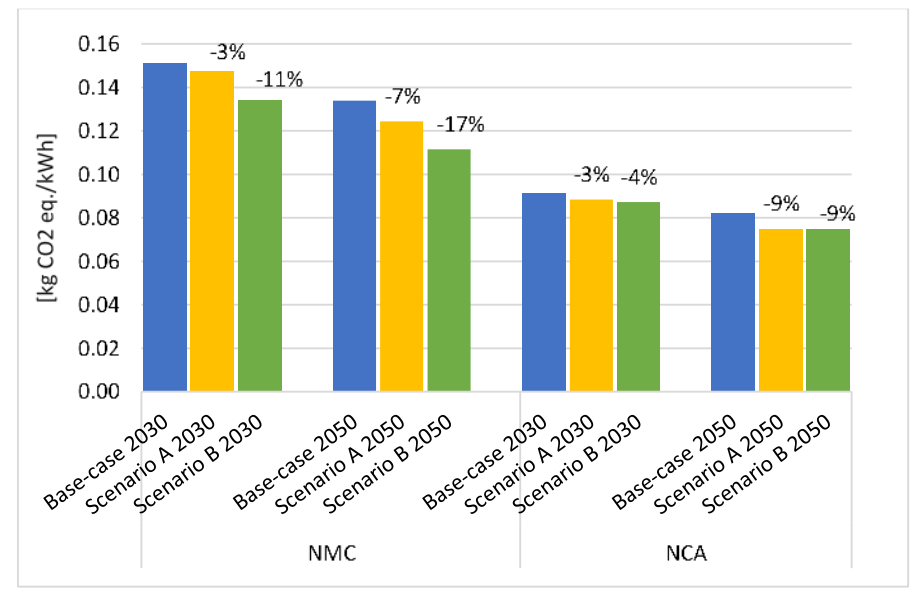

Figure 5. Life-cycle Global Warming Potential (GWP) of NMC and NCA batteries for Base-Case Scenario, Scenario A and Scenario B in different years. Percentages indicates the reduction of GWP impacts with reference to the Base-Case Scenario for the same year. 
The development of second-use of LIBs (Scenario A) confirmed a delay in availability of Li and $\mathrm{Ni}$ for recycling and the consequent decrease of secondary Li and Ni in the EU: in 2050 about 400 tonne of secondary $\mathrm{Li}$ and 9,500 tonne of $\mathrm{Ni}$ will be available (about $0.9 \%$ and $2 \%$ of the $\mathrm{Li}$ and $\mathrm{Ni}$ demand in 2050) (yellow bars in Figure 6). Difference of secondary Li and Ni compared to the Base-Case Scenario are almost null since the stock of LIBs in second-use application will become more relevant around 2040. Finally, from the analysis of stocks and flows of materials, it emerged that the increase of recycling efficiency will result in a significant flow of SRMs (green bars in Figure 6). In this case, the secondary $\mathrm{Li}$ and $\mathrm{Ni}$ in 2050 will be respectively $7 \%$ and $9 \%$ of the $\mathrm{Li}$ and $\mathrm{Ni}$ demand in 2050, i.e., 3000 and 38,000 tonnes.

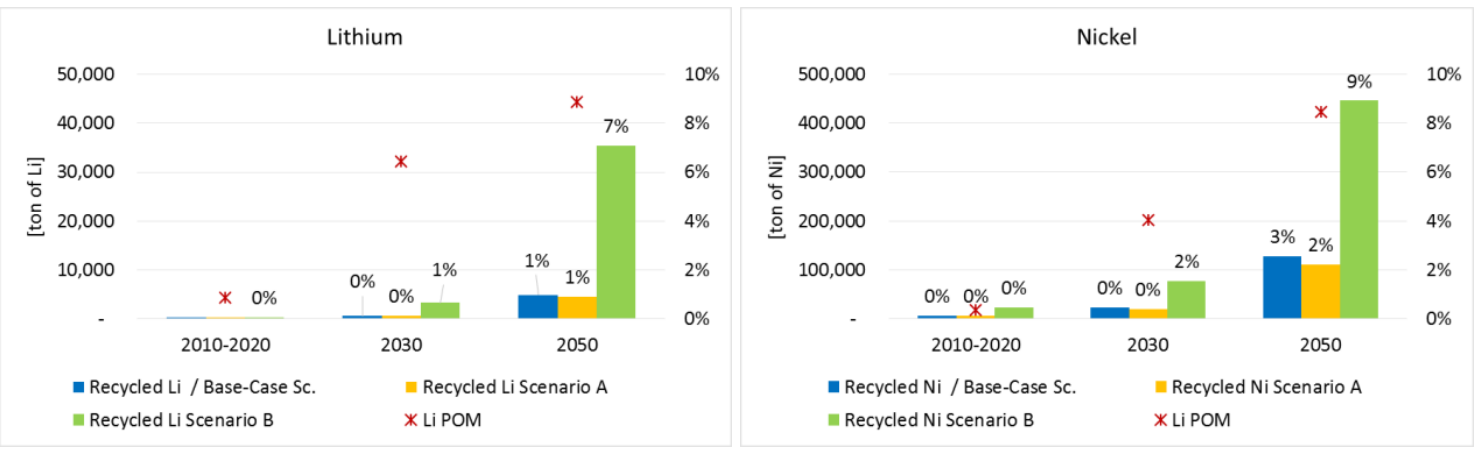

Figure 6. Li and Ni embedded in traction LIBs placed on the EU market (POM) and recovered from recycling processes for the Base-Case Scenario, Scenario A and Scenario B in different years.

Finally, Figure 7 reports the EOL-RIR and the EOL-RR [58] calculated for all the assessed scenarios. The increasing recovery of $\mathrm{Li}$ as SRMs (Scenario B, green bars) significantly increases both indices; a similar result is observed if the technological development of recycling $\mathrm{Ni}$ will allow reaching a high level of purity, i.e., $>99 \%$, in order to use Ni as SRMs for manufacturing new LIBs' cathodes. Note that the amount of materials stocked in second-use application is not importantly affecting the indices since second-use is still a limited EoL option (Scenario A, yellow bars).

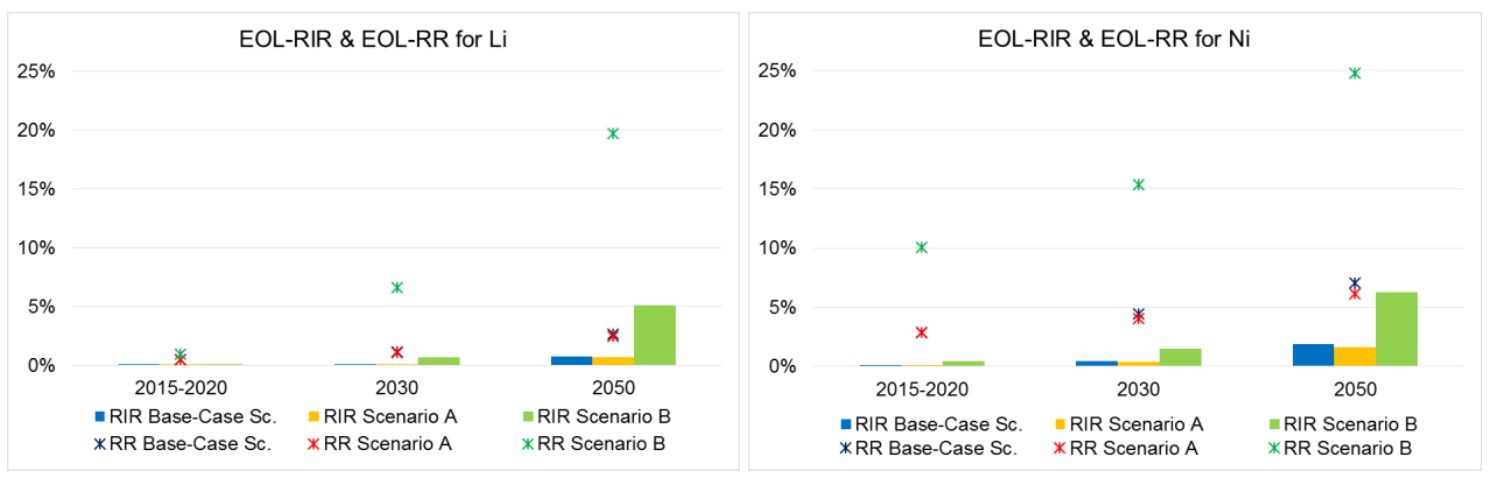

Figure 7. EOL-RIR and EOL RR of Li and Ni according to the Base-Case Scenario, Scenario A and Scenario B in different years.

The EOL-RIR of $\mathrm{Li}$ and $\mathrm{Ni}$ is used to better understand the role of recycling in mitigating the SR in 2050 according to the expected evolution of the EU fleet. The current and future EoL-RIR is estimated by the MFA tool (average 2015-2020) and in the future (2050), based on the assessed scenarios.

The supply risk reduction of $\mathrm{Ni}$ is $<1 \%$ in the Base-Case Scenario (2015-2020) and $6.3 \%$ in Scenario B (2050). Ni used to manufacture LIBs requires a higher grade (Class I) than Ni used in, e.g., steel applications, which is its main use according to the Ni Institute [21] and the overall EoL-RIR is estimated to be about 34\% [84]. Even though the recycling rate (RR) of Ni from LIBs is quite high 
and its trend is rising, the required grade is higher to feed the input for batteries with SRM. Thus, the EoL-RIR can slightly reduce the supply risk.

The figures are quite similar for $\mathrm{Li}$, with a supply risk reduction $<1 \%$ in the Base-Case Scenario (2015-2020) and 5\% in Scenario B (2050).

Moreover, it is well known that the supply risk for $\mathrm{Ni}$ is much lower than that of $\mathrm{Li}$ according to several criticality assessments run internationally [16], thus it appears that recycling as a risk mitigation factor seems even more important for Li than for Ni. Unfortunately, at present and in the future, recycling, alone, does not seem a relevant mitigation factor for the supply risk of neither Li nor $\mathrm{Ni}$ (all other factors being equal, and taking into account the limits of the model).

\subsection{Discussion}

The complexity of batteries and the assessment of their (environmental) performances is certainly a major challenge in this and in other studies. A single assessment tool cannot provide a complete overview of the impacts of LIBs and can unlikely capture all the effects of different EoL options $[29,85]$. This is particularly relevant for those new options that have shown potential to develop in the next future (e.g., second-use of batteries), as well as in case of raw materials with high supply risk (e.g., Li).

LCA and MFA are applied to traction LIBs in the current and future EU fleet, to assess the life-cycle GWP of specific LIBs chemistries currently available in the market and LIBs entering in the EU fleet up to 2050 (Section 3.1); in addition, stocks and flows of LIBs/storage capacity/embedded materials were quantified along the EU value chain of LIBs for different scenarios (Section 3.2). The criticality of materials in this study was used to filter the raw materials to firstly focus on and to assess the supply risk of such materials using data provided by the MFA results. Among the key materials for the future development of batteries [72], those selected for the study are Li and Ni embedded (Section 3.3). Due to the uncertainty of input data related to the fast evolution of the technology, the complexity of the LIBs' components, the globalised market and different assumptions behind available LCA and MFA studies, assessment models are built using modules and parameters. This makes the model flexible and updatable according to available data (e.g., in case of new components/processes/stocks) and addresses uncertainty through the creation of different scenarios (e.g., change in energy mix and increase/decrease of processes efficiency). Obtained results confirm the added value of the adoption of different assessment tools to improve the knowledge of complex systems, as traction LIBs [29,30,32].

Since the vehicle electrification certainly plays an important role in the decarbonisation of mobility, the investigation on the environmental performance of traction batteries is of crucial importance, being the main element that differentiates ICEVs and EVs. The lack of reliable data highlighted by several authors (e.g., Peters et al. [42] and Zackrisson et al. [25]), and therefore the difficulty in consistent comparison between LCIA results is addressed in the study through the adoption of the unified database proposed by Peters and Weil [44], used to assess the GWP of NMC, NCA and LMO/NMC chemistries. To bypass the barriers for information sharing and reuse often caused by the only partial interoperability between the main LCA software and database currently available [86], to ease the replicability of results and to further enlarge the proposed analysis, the LCA tool is provided in the Supplementary Materials as a spreadsheet file. LCIA results obtained for $1 \mathrm{~kg}$ of battery pack (provided in the Supplementary Material) are aligned with the available literature $[24,26,44]$. The results expressed for the F.U. of $1 \mathrm{kWh}$ provided by the battery are not easily comparable with previous literature since most authors did not provide results with this F.U. In addition, it is necessary to underline that LCIA results for $1 \mathrm{kWh}$ of provided energy directly depend on the lifetime of the battery. This latter is fixed in this paper to 20,000 total kWh provided, but can vary among different batteries. This parameter can however be easily modified in the LCA tool provided in the Supplementary Material and according to available data, its variation is recommended to understand its relevance in line to the goal of the analysis. The change of the energy mix plays a key role in decreasing both the manufacturing impacts and the life-cycle impacts of LIBs in 2030 and 2050. In fact, manufacturing LIBs with renewable energy sources (Scenario C) reduces the impacts of LIBs placed on market in 2020 of almost 4000 tonnes of 
$\mathrm{CO}_{2}$ compared to the impacts of LIBs placed on market the same year and manufactured with the current EU energy mix. In addition, the increased share of renewables (Base-Case Scenario) is the most important factor in reducing the life-cycle GWP of NMC and NCA chemistries: respectively, by $24 \%$ and $22 \%$ in 2030 and by $32 \%$ and $30 \%$ in 2050 . To better understand the contribution of LIBs in decreasing the impacts of the EU mobility system in the future, a wider analysis should be performed to include the life-cycle impacts of different types of vehicles, even though this means a further level of uncertainty related to needed assumptions and simplifications, e.g., losing the detail on different chemistries and performances due to the high amount of information to be processed. In addition, electricity mix importantly affects the life-cycle impacts of EV vehicles, thus is a key aspect requiring more in-depth analysis, especially in the case of future energy mix [28]. The developed spreadsheet file can be used to model the contribution of LIBs taking into account key parameters and without losing details about performances of batteries (see Supplementary Information).

In 2030, $32 \mathrm{kt}$ of $\mathrm{Li}$ and $202 \mathrm{kt}$ of $\mathrm{Ni}$ will be required according to the targets established by the EU Long-Term Strategy [4]. These values increase up to $44 \mathrm{kt}$ and $423 \mathrm{kt}$ in 2050. The assessment of different trend of xEVs uptake, as discussed in Section 2, is recommended. In fact, input data concerning materials content in LIBs are currently poor and should be updated with new available data, and it is expected that new technologies will appear in the market, like fuel cell EVs [3,7].

The results of the analysis confirm that the growth of LIBs in the future EU fleet corresponds to an increasing flow of energy storage capacity, which is better exploited through second-use of LIBs [12]. As a consequence of the extension of LIBs' lifetime, $\mathrm{Li}$ and $\mathrm{Ni}$ are locked in the second-use stock, and therefore they cannot be available for recycling and potentially be recovered as SRMs.

Even though LIBs are not second-used, current recycling of $\mathrm{Li}$ is quite poor [73,74] and the secondary $\mathrm{Ni}$ is not pure enough to be used again for LIBs manufacturing [20,21]. In fact, without any improvements in recycling processes (Base-Case Scenario), the contribution of secondary Li and $\mathrm{Ni}$ to the EU materials demand is and will remain quite limited (1\% of the Li demand and $2.5 \%$ of the $\mathrm{Ni}$ demand in 2050). Even though the availability of $\mathrm{Li}$ and $\mathrm{Ni}$ is delayed in time according to the extended lifetime of LIBs in second-use applications (Scenario A), the potential increase of recycling (Scenario B) of Li and Ni entails environmental benefits in terms of GWP (17\% and 9\% of the life-cycle GWP for, respectively, NMC and NCA chemistries in 2050, compared to the GWP of currently LIBs in the market). Moreover, this improvement also means an increasing amount of SRMs, hence a slight mitigation of the supply risk in the future (2050). In fact, although supply risk of $\mathrm{Ni}$ is relatively low at present and the recycling could lead to a more sustainable production, the overall risk would not be affected significantly. The supply risk of Li is very high due to the high concentration of EU sourcing in Chile and completely reliant on import from third countries. Despite a rising trend of $\mathrm{Li}$ in the future, EoL RIR will not be able to mitigate this important supply risk. It can be concluded that, with the aim of pursuing strategies of mitigation, fostering European domestic production and diversifying the EU suppliers seems the best option to reduce the supply risk, rather than the way of recycling.

Batteries require specific grade of materials for their chemistry and a sectorial level assessment would draw a more precise picture for their risk of supply disruption [63]. In addition, the EU consumption of raw materials used in batteries is extremely low compared to other sectors, e.g., Li is mostly consumed by the glass and ceramics industries, and only $1 \%$ feeds the battery industry. $\mathrm{Ni}$ is mainly used to produce different stainless and alloy steels, which is the biggest user of primary and scrap Ni [21]. The Ni consumption in the EU battery industry is negligible compared to the other sectors. Within this context, the competition among sectors which use the same raw materials for different purpose could play an important role to define the supply risk and/or economic vulnerability of battery raw materials. According to Nassar et al. [87], the industry's relative vulnerability can be quantified by calculating "the ratio of an industry's expenditures for a given commodity relative to that industry's profitability". This approach seems to fit well to a sectorial level such as battery manufacturing, although it requires a well-structured breakdown of economic sectors and data availability. 
It is worth noting that assumptions about, e.g., the share of materials recovered in a closed/open-loop, evolution of recycling efficiency, extended lifetime of LIBs, materials content, variation of LIBs capacity, supply data, etc., are based on available literature and often refer to past and current situation. Modularity and parameters in the developed models are used: (1) to make the application of selected tools flexible and updatable according to available data; and (2) to address uncertainty through the creation of different scenarios. Relevant parameters identified in the performed analysis are energy mix, recycling efficiency and supply risk. More efforts are needed to further explore the effects of, e.g., improved lifetime, one of the key parameters identified in the literature $[10,42]$ and future supply risk.

Finally, the proposed approach could in the future be used to enlarge the performed analysis covering more aspects, e.g., different deployment scenarios, improved EoL practices and new materials. An interesting example on new materials expected to be used in manufacturing future traction LIBs is Niobium [88]. Niobium, which belongs to the CRMs list [19], is mainly produced in Brazil and Canada, even though exploration activities are taking place in several countries [89]. Currently, niobium is not massively used for manufacturing batteries, but its application has some potential, e.g., for anodes $[88,90,91]$, which means a potential increase of demand. Very few studies on niobium in batteries are available and environmental impacts are almost unknown [92]. According to the authors' knowledge, the GWP of ferro-niobium were provided by Dolganova [93], who used primary data provided by CBMM (Companhia Brasileira de Metalurgia e Mineração). Such gap of data requires more efforts in assessing the environmental impacts of niobium for batteries, but also in investigating various aspects affecting both MFA and its supply, e.g., niobium content in anodes, which materials it will substitute (see Table 2).

Overall, the combination of information provided by different tools and experts in different fields, as well as the assessment of different scenarios, is recommended to identify key aspects that can contribute to decrease the environmental impacts of a strategic sector for the EU, such as mobility.

\section{Conclusions}

LCA, MFA and criticality (supply risk) considerations are contrasted and discussed in a mutually interactive manner, with focus on the environmental impacts of traction LIBs and some of their constituting materials in the current and future EU fleet from different perspectives. Modules and parameters used in both the LCA and MFA models allow identifying relevant aspects in terms of impacts and assessing different scenarios, including different possible EoL options. Criticality mainly contributes to prioritise materials to be studied and improve knowledge on the potential contribution of SRMs in the supply risk for specific materials.

The Supplementary Materials support the replicability of the assessment, as well as future studies. Users can easily access to relevant information on both the LCI and LCIA results, being able to: (1) directly compare input/output flows of the life-cycle of different LIBs; (2) further enlarge the assessment; and (3) modify and/or add input/output flows. The dynamic MFA tool describes the value chain of traction LIBs in the EU including all EoL options, and it allows quantifying the stocks and flows of LIBs/energy storage capacity/embedded materials in the EU for different scenarios and under different assumptions. Criticality assessments run worldwide suggested to initially focus on $\mathrm{Li}$ and $\mathrm{Ni}$ as key raw materials embedded in LIBs. The paper provided information of the role of recycling as mitigation factor of the supply risk of both $\mathrm{Li}$ and Ni used in LIBs.

Results point out that the life-cycle GWP of traction LIBs will likely improve in the future, mainly due to more environmental-friendly energy mix and improved LIBs' recycling. Even though second-use will postpone the availability of materials for recycling, recycling improvement can importantly increase the flows of SRMs, boosting resource efficiency and keeping the values of materials in the EU. In addition, recycling can further contribute to reducing the supply risk of both $\mathrm{Li}$ and $\mathrm{Ni}$ in 2050. Such enhancements are related to both the development of recycling technologies at large scale (in case of $\mathrm{Li}$ ) and the higher grade of recovered materials (in case of $\mathrm{Ni}$ ). 
Lack of knowledge about the LIBs value chain, lack of robust data as input for the assessments and adoption of data based on past and current trends are importantly reflected in the obtained results, thus suggesting to intensify research efforts. Obviously, further methodological work, concerning, e.g., scenario setting, uptake and impacts of future technologies, adoption of consequential LCA, substitution of materials, effects of stocks and flows, etc. would also be advisable to appropriately support more prospective decision-making.

Both the literature review and the performed analysis confirmed the added-value of performing a multi-criteria analysis, especially when addressing complex systems. Involvement of different expertise and running scenarios varying relevant parameters are keys in updating both the modelling and the input data in order to provide reliable information to identify circular economy aspects that support decision making to properly manage the whole value chain of a strategic sector for the EU, such as batteries for e-mobility.

Supplementary Materials: The following tables in excel file that provides the main assumptions of the assessment reported in this paper are available online at http://www.mdpi.com/1996-1073/13/10/2513/s1. Moreover, to make the LCA replicable and updatable, the LCI of each LIB chemistry is provided in the spreadsheets of this excel file, where each input/output flow of material, energy, waste and emission is related to $1 \mathrm{~kg}$ of battery pack.Each flow is connected to the related impacts, enabling the automatic calculation of the impact of the battery life-cycle. The LCIA for all the impact categories included in the assessment are reported in the last spreadsheet ("Impact_calculation").

Author Contributions: Conceptualization, S.B., G.A.B. and I.B.; methodology, S.B., G.A.B., I.B. and U.E.; validation, G.A.B. and F.M.; investigation, S.B., G.A.B., I.B. and U.E.; resources, F.M.; data curation, S.B., I.B., U.E. and S.C.; writing - original draft preparation, S.B., I.B. and U.E.; writing-review and editing, G.A.B, F.M. and S.C.; visualization, S.B., I.B. and U.E.; supervision, G.A.B. and F.M.; project administration, G.A.B. and F.M. All authors have read and agreed to the published version of the manuscript.

Funding: This research received no external funding.

Conflicts of Interest: The authors declare no conflict of interest.

Disclaimer: The views expressed in the article are personal and do not necessarily reflect an official position of the European Commission.

\section{References}

1. EC. Communication from the Commission to the European Parliament, the European Council, the Council, the European economic and social Committee and the Committee of the Regions. The European Green Deal; COM(2019) 640; Publications Office of the EU: Luxemburg, 2019.

2. EC. Reflection Paper-Towards a Sustainable Europe By 2030; COM(2019) 22 final; Publications Office of the EU: Luxemburg, 2019.

3. Alonso Raposo, M.; Ciuffo, B.; Ardente, F.; Aurambout, J.P.; Baldini, G.; Braun, R.; Christidis, P.; Christodoulou, A.; Duboz, A.; Felici, S.; et al. The Future of Road Transport_Implications of Automated, Connected, Low-Carbon and Shared Mobility; Publications Office of the EU: Luxemburg, 2019; ISBN 978-92-76-03409-4.

4. EC. In-Depth Analysis in Support of the Commission Communication COM(2018) 773-A Clean Planet for all A European Long-Term Strategic Vision for a Prosperous, Modern, Competitive and Climate Neutral Economy; Publications Office of the EU: Luxemburg, 2018.

5. Zubi, G.; Dufo-López, R.; Carvalho, M.; Pasaoglu, G. The lithium-ion battery: State of the art and future perspectives. Renew. Sustain. Energy Rev. 2018, 89, 292-308. [CrossRef]

6. Witkamp, B.; van Gijlswijk, R.; Bolech, M.; Coosemans, T.; Hooftman, N. The transition to a Zero Emission Vehicles fleet for cars in the EU by 2050. In Pathways and Impacts: An Evaluation of Forecasts and Backcasting the COP21 Commitments; European Alternative Fuel Observatory (EAFO): Brussels, Belgium, 2017.

7. Cano, Z.P.; Banham, D.; Ye, S.; Hintennach, A.; Lu, J.; Fowler, M.; Chen, Z. Batteries and fuel cells for emerging electric vehicle markets. Nat. Energy 2018, 3, 279-289. [CrossRef]

8. Thiel, C.; Nijs, W.; Simoes, S.; Schmidt, J.; van Zyl, A.; Schmid, E. The impact of the EU car CO2 regulation on the energy system and the role of electro-mobility to achieve transport decarbonisation. Energy Policy 2016, 96, 153-166. [CrossRef] 
9. Bobba, S.; Mathieux, F.; Ardente, F.; Blengini, G.A.; Cusenza, M.A.; Podias, A.; Pfrang, A. Life Cycle Assessment of repurposed electric vehicle batteries: An adapted method based on modelling energy flows. J. Energy Storage 2018, 19, 213-225. [CrossRef]

10. Podias, A.; Pfrang, A.; Di Persio, F.; Kriston, A.; Bobba, S.; Mathieux, F.; Messagie, M.; Boon-Brett, L. Sustainability Assessment of Second Use Applications of Automotive Batteries: Ageing of Li-Ion Battery Cells in Automotive and Grid-Scale Applications. World Electr. Veh. J. 2018, 9, 24. [CrossRef]

11. EUROBAT. E-Mobility Battery R\&D Roadmap 2030-Battery Technology for Vehicle Applications; Association of European Automotive and Industrial Battery Manufacturers (EUROBAT). Available online: https: //eurobat.org/sites/default/files/e-mobility_roadmap_presentation_olivier_amiel_final.pdf (accessed on 2015).

12. Bobba, S.; Mathieux, F.; Blengini, G.A. How will second-use of batteries affect stocks and flows in the EU? A model for traction Li-ion batteries. Resour. Conserv. Recycl. 2019, 145, 279-291. [CrossRef] [PubMed]

13. EC. Communication from the Commission to the European Parliament, the European Council, the Council, the European economic and social Committee and the Committee of the Regions; A new Circular Economy Action Plan; For a cleaner and more competitive Europe; COM: 2020/98 final; Publications Office of the EU: Luxemburg, 2020.

14. Winslow, K.M.; Laux, S.J.; Townsend, T.G. A review on the growing concern and potential management strategies of waste lithium-ion batteries. Resour. Conserv. Recycl. 2018, 129, 263-277. [CrossRef]

15. EC. Communication from the Commission to the European Parliament, the European Council, the Council, the European economic and social Committee and the Committee of the Regions; A New Industrial Strategy for Europe; COM: 2020; 102 final; Publications Office of the EU: Luxemburg, 2020.

16. Schrijvers, D.; Hool, A.; Blengini, G.A.; Chen, W.-Q.; Dewulf, J.; Eggert, R.; van Ellen, L.; Gauss, R.; Goddin, J.; Habib, K.; et al. A review of methods and data to determine raw material criticality. Resour. Conserv. Recycl. 2020, 155, 104617. [CrossRef]

17. IEA. Global EV Outlook 2018: Towards Cross-Modal Electrification; International Energy Agency (IEA): Paris, France, 2018; ISBN 9789264302365.

18. Olivetti, E.A.; Ceder, G.; Gaustad, G.G.; Fu, X. Lithium-Ion Battery Supply Chain Considerations: Analysis of Potential Bottlenecks in Critical Metals. Joule 2017, 1, 229-243. [CrossRef]

19. EC. Communication from the Commission to the European Parliament, the Council, the European Economic and Social Committee and the Committee of the Regions on the 2017 list of Critical Raw Materials for the EU; COM: 2017; 490 final; Publications Office of the EU: Luxemburg, 2017.

20. Mistry, M.; Gediga, J.; Boonzaier, S. Life cycle assessment of nickel products. Int. J. Life Cycle Assess. 2016, 21, 1559-1572. [CrossRef]

21. INSG. International Nickel Study Group-The World Nickel Factbook 2018. 2018. Available online: https://insg.org/wp-content/uploads/2019/03/publist_The-World-Nickel-Factbook-2018.pdf (accessed on 15 May 2020).

22. Ellingsen, L.A.-W.; Hung, C.R. Research for TRAN Committee-Battery-Powered Electric Vehicles: Market Development and Lifecycle Emissions. European Union, 2018. Available online: https://www.europarl. europa.eu/RegData/etudes/STUD/2018/617457/IPOL_STU(2018)617457_EN.pdf (accessed on 15 May 2020).

23. Mathieux, F.; Ardente, F.; Bobba, S.; Nuss, P.; Blengini, G.A.; Alves Dias, P.; Blagoeva, D.; Torres De Matos, C.; Wittmer, D.; Pavel, C.; et al. Critical Raw Materials and the Circular Economy_Background Report; JRC-EC (Joint Research Centre-European Commission) Science-for-Policy Report, EUR 28832 EN; Publications Office of the European Union: Luxembourg, 2017; ISBN 9789279742828.

24. Ellingsen, L.A.-W.; Majeau-Bettez, G.; Singh, B.; Srivastava, A.K.; Valøen, L.O.; Strømman, A.H. Life Cycle Assessment of a Lithium-Ion Battery Vehicle Pack: LCA of a Li-Ion Battery Vehicle Pack. J. Ind. Ecol. 2014, 18, 113-124. [CrossRef]

25. Zackrisson, M.; Avellán, L.; Orlenius, J. Life cycle assessment of lithium-ion batteries for plug-in hybrid electric vehicles - Critical issues. J. Clean. Prod. 2010, 18, 1519-1529. [CrossRef]

26. Majeau-Bettez, G.; Hawkins, T.R.; Strømman, A.H. Life Cycle Environmental Assessment of Lithium-Ion and Nickel Metal Hydride Batteries for Plug-In Hybrid and Battery Electric Vehicles. Environ. Sci. Technol. 2011, 45, 4548-4554. [CrossRef]

27. Ruiz, V.; Boon-Brett, L.; Steen, M.; Berghe, L. Van den Putting Science into Standards: Workshop-Summary \& Outcomes. In Proceedings of the Driving Towards Decarbonisation of Transport: Safety, Performance, Second life and Recycling of Automotive Batteries for e-Vehicles, Workshop Organised by JRC and CEN-CENELEC JRC, Petten, The Netherlands, 22-23 September 2016. 
28. Marmiroli, B.; Messagie, M.; Dotelli, G.; Van Mierlo, J. Electricity Generation in LCA of Electric Vehicles: A Review. Appl. Sci. 2018, 8, 1384. [CrossRef]

29. Ardente, F.; Tecchio, P.; Bobba, S.; Mathieux, F. Assessment of resource efficiency in a life cycle perspective: The case of reuse. In Proceedings of the Atti del XI Convegno della Rete Italiana LCA-Resource Efficiency e Sustainable Development Goals: Il ruolo del Life Cycle Thinking, ENEA, Siena, Italy, 22-23 June 2017; ISBN 978-88-8286-352-4.

30. Nuss, P.; Blengini, G.A. Towards better monitoring of technology critical elements in Europe: Coupling of natural and anthropogenic cycles. Sci. Total Environ. 2018, 613, 569-578. [CrossRef] [PubMed]

31. De Meester, S.; Nachtergaele, P.; Debaveye, S.; Vos, P.; Dewulf, J. Using material flow analysis and life cycle assessment in decision support: A case study on WEEE valorization in Belgium. Resour. Conserv. Recycl. 2019, 142, 1-9. [CrossRef]

32. Mancini, L.; Benini, L.; Sala, S. Resource footprint of Europe: Complementarity of material flow analysis and life cycle assessment for policy support. Environ. Sci. Policy 2015, 54, 367-376. [CrossRef]

33. Ramirez, D.A.B.; Ochoa, G.E.V.; Peña, A.R.; Escorcia, Y.C. Bibliometric analysis of nearly a decade of research in electric vehicles: A dynamic approach. ARPN J. Eng. Appl. Sci. 2018, 13, 4730-4736.

34. Zhao, X.; Wang, S.; Wang, X. Characteristics and Trends of Research on New Energy Vehicle Reliability Based on the Web of Science. Sustainability 2018, 10, 3560. [CrossRef]

35. Schmitt, G.; Scott, J.; Davis, A.; Utz, T. Patents and progress; intellectual property showing the future of electric vehicles. In Proceedings of the EVS29 Symposium, Montréal, QC, Canada, 19-22 June 2016; Volume 8, pp. 635-645.

36. Messagie, M.; Boureima, F.S.; Coosemans, T.; Macharis, C.; Mierlo, J. Van A range-based vehicle life cycle assessment incorporating variability in the environmental assessment of different vehicle technologies and fuels. Energies 2014, 7, 1467-1482. [CrossRef]

37. Harvey, L.D.D. Resource implications of alternative strategies for achieving zero greenhouse gas emissions from light-duty vehicles by 2060. Appl. Energy 2018, 212, 663-679. [CrossRef]

38. Notter, D.A.; Gauch, M.; Widmer, R.; Wäger, P.; Stamp, A.; Zah, R.; Althaus, H.-J. Contribution of Li-Ion Batteries to the Environmental Impact of Electric Vehicles. Environ. Sci. Technol. 2010, 44, 6550-6556. [CrossRef] [PubMed]

39. Girardi, P.; Gargiulo, A.; Brambilla, P.C. A comparative LCA of an electric vehicle and an internal combustion engine vehicle using the appropriate power mix: The Italian case study. Int. J. Life Cycle Assess. 2015, 20, 1127-1142. [CrossRef]

40. ISO 14040:2006. Environmental Management_Life Cycle Assessment_Requirements and Guidelines; UNI EN ISO (International Standard Organisation), 2006.

41. Recharge Association. PEFCR-Product Environmental Footprint Category Rules for High Specific Energy Rechargeable Batteries for Mobile Applications. 2018. Available online: https://ec.europa.eu/environment/ eussd/smgp/pdf/PEFCR_Batteries.pdf (accessed on 15 May 2020).

42. Peters, J.F.; Baumann, M.; Zimmermann, B.; Braun, J.; Weil, M. The environmental impact of Li-Ion batteries and the role of key parameters-A review. Renew. Sustain. Energy Rev. 2017, 67, 491-506. [CrossRef]

43. Ellingsen, L.A.-W.; Hung, C.R.; Strømman, A.H. Identifying key assumptions and differences in life cycle assessment studies of lithium-ion traction batteries with focus on greenhouse gas emissions. Transp. Res. Part D Transp. Environ. 2017, 55, 82-90. [CrossRef]

44. Peters, J.F.; Weil, M. Providing a common base for life cycle assessments of Li-Ion batteries. J. Clean. Prod. 2018, 171, 704-713. [CrossRef]

45. Cusenza, M.A.; Bobba, S.; Ardente, F.; Cellura, M.; Di Persio, F. Energy and environmental assessment of a traction lithium-ion battery pack for plug-in hybrid electric vehicles. J. Clean. Prod. 2019, 215, 634-649. [CrossRef]

46. Philippot, M.; Álvarez, G.; Ayerbe, E.; Van Mierlo, J.; Messagie, M. Eco-Efficiency of a Lithium-Ion Battery for Electric Vehicles: Influence of Manufacturing Country and Commodity Prices on GHG Emissions and Costs. Batteries 2019, 5, 23. [CrossRef]

47. Deng, Y.; Li, J.; Li, T.; Gao, X.; Yuan, C. Life cycle assessment of lithium sulfur battery for electric vehicles. J. Power Sources 2017, 343, 284-295. [CrossRef] 
48. Wang, Q.; Liu, W.; Yuan, X.; Tang, H.; Tang, Y.; Wang, M.; Zuo, J.; Song, Z.; Sun, J. Environmental impact analysis and process optimization of batteries based on life cycle assessment. J. Clean. Prod. 2018, 174, 1262-1273. [CrossRef]

49. EC. Commission Staff working document Accompanying the document Communication from the Commission to the European Parliament, the Council, the European Economic and Social Committee and the Committee of the Regions EUROPE ON THE MOVE An Agenda for a Socially; SWD: 2017; 177 final; Publications Office of the EU: Luxemburg, 2017.

50. Faria, R.; Marques, P.; Garcia, R.; Moura, P.; Freire, F.; Delgado, J.; de Almeida, A.T. Primary and secondary use of electric mobility batteries from a life cycle perspective. J. Power Sources 2014, 262, 169-177. [CrossRef]

51. Erkisi-Arici, S.; Egede, P.; Cerdas, F.; Kaluza, A.; Herrmann, C. Life Cycle Assessment of Electric Vehicles-The Influence of Regional Aspects and Future Renewable Energy Targets. In Proceedings of the EVS30 Symposium, Stuttgart, Germany, 9-11 October 2017.

52. Ahmadi, L.; Yip, A.; Fowler, M.; Young, S.B.; Fraser, R.A. Environmental feasibility of re-use of electric vehicle batteries. Sustain. Energy Technol. Assess. 2014, 6, 64-74. [CrossRef]

53. Casals, L.C.; Amante García, B.; Canal, C. Second life batteries lifespan: Rest of useful life and environmental analysis. J. Environ. Manag. 2019, 232, 354-363. [CrossRef]

54. Koch-Ciobotaru, C.; Saez-de-Ibarra, A.; Martinez-Laserna, E.; Stroe, D.-I.; Swierczynski, M.; Rodriguez, P. Second life battery energy storage system for enhancing renewable energy grid integration. In Proceedings of the 2015 IEEE Energy Conversion Congress and Exposition (ECCE), Montreal, QC, Canada, 20-24 September 2015; pp. 78-84. [CrossRef]

55. Weniger, J.; Tjaden, T.; Quaschning, V. Sizing of residential PV battery systems. Energy Procedia 2014, 46, 78-87. [CrossRef]

56. UMICORE. Battery Recycling-Our Recycling Process. Available online: http://csm.umicore.com/en/ recycling/battery-recycling/our-recycling-process/ (accessed on 15 February 2020).

57. EC. The Raw Materials Initiative-Meeting our Critical Needs for Growth and Jobs in Europe; COM: 2008; 699 final; Publications Office of the EU: Luxemburg, 2008.

58. Blengini, G.A.; Blagoeva, D.; Dewulf, J.; Torres de Matos, C.; Baranzelli, C.; Ciupagea, C.; Dias, P.; Kayam, Y.; Latunussa, C.E.L.; Mancini, L.; et al. Methodology for establishing the EU list of Critical Raw Materials. Publ. Off. Eur. Union 2017.

59. Turner, D.A.; Williams, I.D.; Kemp, S. Combined material flow analysis and life cycle assessment as a support tool for solid waste management decision making. J. Clean. Prod. 2016, 129, 234-248. [CrossRef]

60. Mancini, L.; Sala, S.; Recchioni, M.; Benini, L.; Goralczyk, M.; Pennington, D. Potential of life cycle assessment for supporting the management of critical raw materials. Int. J. Life Cycle Assess. 2015, 20, 100-116. [CrossRef]

61. Golroudbary, S.R.; Calisaya-Azpilcueta, D.; Kraslawski, A. The life cycle of energy consumption and greenhouse gas emissions from critical minerals recycling: Case of lithium-ion batteries. Procedia CIRP 2019, 80, 316-321. [CrossRef]

62. Pillot, C. Lithium ion Battery Raw Material Supply and Demand 2016-2025. In Proceedings of the 7th International AABC Advanced Automotive battery Conference, Mainz, Germany, 12-16 January 2017.

63. Song, J.; Yan, W.; Cao, H.; Song, Q.; Ding, H.; Lv, Z.; Zhang, Y.; Sun, Z. Material flow analysis on critical raw materials of lithium-ion batteries in China. J. Clean. Prod. 2019, 215, 570-581. [CrossRef]

64. Helbig, C.; Bradshaw, A.M.; Wietschel, L.; Thorenz, A.; Tuma, A. Supply risks associated with lithium-ion battery materials. J. Clean. Prod. 2018, 172, 274-286. [CrossRef]

65. Gemechu, E.D.; Sonnemann, G.; Young, S.B. Geopolitical-related supply risk assessment as a complement to environmental impact assessment: The case of electric vehicles. Int. J. Life Cycle Assess. 2017, 22, 31-39. [CrossRef]

66. Eynard, U.; Bobba, S.; Cusenza, M.A.; Blengini, G.A. Lithium-ion batteries for electric vehicles: Combining Environmental and Social Life Cycle Assessments. In Proceedings of the Life Cycle Thinking in Decision-Making for Sustainability: From Public Policies to Private Businesses, Messina, Italy, 11-12 June 2018.

67. Gaines, L. Lithium-ion battery recycling processes: Research towards a sustainable course. Sustain. Mater. Technol. 2018, 17, e00068. [CrossRef]

68. Bauer, C. Ökobilanz von Lithium-Ionen Batterien; Paul Scherrer Institut, Labor für Energiesystem-Analysen (LEA): Villigen, Switzerland, 2010. 
69. Banja, M.; Jégard, M. Renewable technologies in the EU electricity sector: trends and projections. In Analysis in the Framework of the EU 2030 Climate and Energy Strategy; EUR 28897 EN; Publications Office of the European Union: Luxemburg, 2017.

70. Decker, M.; Vasakova, L. Energy Roadmap 2050. Impact assessment and scenario analysis. In Eur. Comm. Energy Unit A1 Energy Policy Anal Commission Staff Working Paper, SEC(2011) 1565 final; Publications Office of the European Union: Luxemburg, 2011.

71. Nakamura, S.; Kondo, Y.; Kagawa, S.; Matsubae, K.; Nakajima, K.; Nagasaka, T. MaTrace: Tracing the fate of materials over time and across products in open-loop recycling. Environ. Sci. Technol. 2014, 48, 7207-7214. [CrossRef] [PubMed]

72. EC. Report on Raw Materials for Battery Applications; Commission Staff Working Document SWD(2018) 245; Publications Office of the European Union: Brussels, Belgium, 2018.

73. Dahllöf, L.; Romare, M.; Wu, A. Mapping Lithium-Ion Batteries for Vehicles: A study of their Fate in the Nordic Countries; Lithium-Ion Batter; Nordic Council of Ministers: Copenhagen, Demark, 2019.

74. Lebedeva, N.; Di Persio, F.; Boon-Brett, L. Lithium Ion Battery Value Chain and Related Opportunities for Europe; EUR 28534 EN; Publications Office of the European Union: Luxembourg, 2017; ISBN 9789279669484.

75. Schitech Europa 99\% Metal Purity Achieved from Recycled Batteries. Available online: https://www. scitecheuropa.eu/99-metal-purity-achieved-from-recycled-batteries/98373/ (accessed on 14 February 2020).

76. Campagnol, N.; Hoffman, K.; Lala, A.; Ramsbottom, O. The Future of Nickel: A Class Act. 2017. Available online: https://www.mckinsey.com/industries/metals-and-mining/our-insights/the-future-of-nickel-a-classact (accessed on 15 May 2020).

77. Berckmans, G.; Messagie, M.; Smekens, J.; Omar, N.; Vanhaverbeke, L.; Van Mierlo, J. Cost projection of state of the art lithium-ion batteries for electric vehicles up to 2030. Energies 2017, 10, 1314. [CrossRef]

78. Green Car Congress Audi and Umicore Start Closed Loop for Cobalt and Nickel, More than $90 \%$ of Co and Ni in e-tron Batteries can be Recovered. Available online: https://www.greencarcongress.com/2019/12/ 20191218-audiumicore.html (accessed on 15 February 2020).

79. Bobba, S.; Andreas, P.; Persio, F.D.; Maarten, M.; Paolo, T.; Cusenza, M.; Umberto, E.; Fabrice, M. Sustainability Assessment of Second Life Applications of Automotive Batteries (SASLAB); Publications Office of the European Union: Luxembourg, 2018; ISBN 978-92-79-92835-2.

80. Arvidsson, R.; Janssen, M.; Svanström, M.; Johansson, P.; Sandén, B.A. Energy use and climate change improvements of Li/S batteries based on life cycle assessment. J. Power Sources 2018, 383, 87-92. [CrossRef]

81. Kim, H.C.; Wallington, T.J.; Arsenault, R.; Bae, C.; Ahn, S.; Lee, J. Cradle-to-Gate Emissions from a Commercial Electric Vehicle Li-Ion Battery: A Comparative Analysis. Environ. Sci. Technol. 2016, 50, 7715-7722. [CrossRef]

82. Dai, Q.; Kelly, J.C.; Gaines, L.; Wang, M. Life cycle analysis of lithium-ion batteries for automotive applications. Batteries 2019, 5, 48. [CrossRef]

83. Kurland, S.D. Energy use for GWh-scale lithium-ion battery production. Environ. Res. Commun. 2019, 2, 12001. [CrossRef]

84. EC. Study on the Review of the List of Critical Raw Materials. Non-Critical Raw Materials Factsheets; Publications Office of the European Union: Luxembourg, 2017; ISBN 978-92-79-47937-3.

85. Mayer, A.; Haas, W.; Wiedenhofer, D.; Krausmann, F.; Nuss, P.; Blengini, G.A. Measuring Progress towards a Circular Economy: A Monitoring Framework for Economy-wide Material Loop Closing in the EU28. J. Ind. Ecol. 2018, 3, 62-76. [CrossRef]

86. Kuczenski, B.; Davis, C.B.; Rivela, B.; Janowicz, K. Semantic catalogs for life cycle assessment data. J. Clean. Prod. 2016, 137, 1109-1117. [CrossRef]

87. Nassar, N.T.; Brainard, J.; Gulley, A.; Manley, R.; Matos, G.; Lederer, G.; Bird, L.R.; Pineault, D.; Alonso, E.; Gambogi, J.; et al. Evaluating the mineral commodity supply risk of the U.S. Manufacturing sector. Sci. Adv. 2020, 6, 8. [CrossRef] [PubMed]

88. Li, J.; Liu, W.W.; Zhou, H.M.; Liu, Z.Z.; Chen, B.R.; Sun, W.J. Anode material NbO for Li-ion battery and its electrochemical properties. Rare Met. 2018, 37, 118-122. [CrossRef]

89. Deloitte Sustainability, British Geological Survey (BGS), Bureau de Recherches Géologiques et Minières (BRGM), Netherlands Organisation for Applied Scientific Research (TNO) Study on the review of the list of Critical Raw Materials; Critical Raw Materials Factsheets; Publications Office of the European Union: Luxembourg, 2017.

90. CBMM Niobium application in Lithium-ion batteries: Anodes, cathodes and solid-state electrolytes. In Proceedings of the International Conference on Niobium Based Batteries, Beijing, China, 11 August 2019. 
91. NiobiumTech. Niobium in Lithium-ion Batteries. Available online: https://niobium.tech/en/Pages/GatewayPages/PDF/Briefings/Niobium_in_Li-Ion_Batteries (accessed on 15 February 2018).

92. Nuss, P.; Eckelman, M.J. Life cycle assessment of metals: A scientific synthesis. PLoS ONE 2014, 9, e101298. [CrossRef] [PubMed]

93. Dolganova, I.; Bosch, F.; Bach, V.; Baitz, M.; Finkbeiner, M. Life cycle assessment of ferro niobium. Int. J. Life Cycle Assess. 2020, 25, 611-619. [CrossRef] 